Review

\title{
Jumping Locomotion Strategies: From Animals to Bioinspired Robots
}

\author{
Xiaojuan Mo ${ }^{1} \mathbb{1}$, Wenjie Ge ${ }^{1, *}$, Marco Miraglia ${ }^{2}$, Francesco Inglese ${ }^{2}$, Donglai Zhao ${ }^{1}$, \\ Cesare Stefanini ${ }^{2,3,4}$ and Donato Romano $2,3, *$ (D) \\ 1 School of Mechanical Engineering, Northwestern Polytechnical University, Xi'an 710072, China; \\ momo152562@mail.nwpu.edu.cn (X.M.); dl_zhao@mail.nwpu.edu.cn (D.Z.) \\ 2 The BioRobotics Institute, Sant'Anna School of Advanced Studies, 56025 Pisa, Italy; \\ marco.miraglia@santannapisa.it (M.M.); francesco.inglese@santannapisa.it (F.I.); \\ cesare.stefanini@santannapisa.it (C.S.) \\ 3 Department of Excellence in Robotics and A.I., Sant'Anna School of Advanced Studies, 56127 Pisa, Italy \\ 4 Healthcare Engineering Innovation Center (HEIC), Khalifa University, Abu Dhabi 127788, UAE \\ * Correspondence: gwj@nwpu.edu.cn (W.G.); donato.romano@santannapisa.it (D.R.)
}

Received: 10 September 2020; Accepted: 28 October 2020; Published: 1 December 2020

\begin{abstract}
Jumping is a locomotion strategy widely evolved in both invertebrates and vertebrates. In addition to terrestrial animals, several aquatic animals are also able to jump in their specific environments. In this paper, the state of the art of jumping robots has been systematically analyzed, based on their biological model, including invertebrates (e.g., jumping spiders, locusts, fleas, crickets, cockroaches, froghoppers and leafhoppers), vertebrates (e.g., frogs, galagoes, kangaroos, humans, dogs), as well as aquatic animals (e.g., both invertebrates and vertebrates, such as crabs, water-striders, and dolphins). The strategies adopted by animals and robots to control the jump (e.g., take-off angle, take-off direction, take-off velocity and take-off stability), aerial righting, land buffering, and resetting are concluded and compared. Based on this, the developmental trends of bioinspired jumping robots are predicted.
\end{abstract}

Keywords: jumping; animal; robotics; bioinspiration; biomimetics

\section{Introduction}

Animals' locomotion is robust, complex, and adaptive. Based on the different environmental scenarios, locomotion can be classified into three categories: (i) terrestrial locomotion; (ii) natural flight; (iii) swimming [1-4]. Compared to flight and swimming [5], terrestrial locomotion is much more complex and more adaptive as a consequence of the environments' complexity and higher competition among terrestrial animals. Terrestrial locomotion includes walking, running (bipeds running and quadrupeds running), jumping (leaping and hopping), climbing, balancing and crawling, etc. [6].

Compared to other terrestrial locomotion modes, jumping permits better adaption to unstructured environments, stronger ability to overcome obstacles, and faster threats avoidance [2,7]. Jumping requires a very short-time energy density. In nature, jumping is often combined with other locomotion modes such as walking, gliding, and flapping. In some cases, jumping represents itself the main locomotion mode, like in kangaroos and galagoes, while in others it is used to assist the main locomotion mode. The latter is, for example, the case of locusts, which exploit jumping to initiate flight. Jumping can help vertebrate and invertebrate animals overcome obstacles that, in some cases, are several times their body size, enabling them to perform fast movements, precious for escaping from predators and for catching scattered food.

Jumping animals use different jumping strategies based on their own body and locomotor structures: (i) Continuous jumping; it is, for instance, the case of kangaroos, that can achieve 
energy accumulation and continuous posture adjustment during both take-off and landing phases [8]; (ii) Intermittent jumping, mainly adopted by small animals, such as locusts and frogs, that need to reaccumulate energy after landing. This energy, in insects ranging from a mass of $1 \mathrm{mg}$ (like fleas) to a mass of $2.5 \mathrm{~g}$ (like locusts) is accumulated in highly specialized energy storage components and then suddenly released to perform powerful jumps [9].

The research in this area is mainly focused on the jumping mechanisms of animals and jumping robots' design. The advantages of jumping locomotion and the excellent jumping ability of animals inspired engineers to develop jumping robots mimicking those animals. Compared to robots using conventional locomotion, e.g., wheels, walking and crawling etc., jumping robots can better adapt to unstructured environments because they can reach goals even in presence of only sparse footholds, by jumping from one to another [7]. Jumping robots are particularly indicated for applications characterized by uneven, rough terrain [10], such as battlefield reconnaissance, archaeological exploration, antiterrorism operations, freight transportation, patient care, disaster relief [11]. They can also be employed in interstellar detection [12], since jumping owes greater advantage over other locomotion modes in low-gravity environments, such as Mars and the moon.

Research on jumping robotic artefacts was initiated by NASA in 1969 [13]. In that occasion, a jumping robot was embarked in Apollo series to be used for moon's surface exploration. The earliest studies, "3D hopper" [14] and "Acrobot" [15], were developed in the 1980s. "3D hopper" presented a rotation joint between the foot and body and another translation joint along the leg, pointing to the body. It could realize jumping and landing in a vertical plane, with the possibility to add a hinge joint for motion in three-dimensional space. "Acrobot", instead, was modeled as double pendulum, with only one actuated joint to keep balance and make power synchronously. Several significant theories and designs had been developed based on these two jumping robots [16-20], but studies were hardly able to build practical and useful experimental platforms, because there were too many assumptions at the basis of their model that were not possible in the real world [21].

In recent years, a lot of new studies on bioinspired-jumping robots have been developed and, based on the design motivation, they can be classified into two subcategories: jumping crafts [22-26] and "in artefacto" $[27,28]$ for studying the biomechanics of jumping animals. There is an increasing number of jumping robots designed from a real application point of view. Yamada et al. designed several jumping robots based on the snap-through buckling of closed elastics [22-26]. Sugiyama et al. developed both two-dimension and three-dimension crawling and jumping robots using shape memory alloy (SMA) wires and investigated the influence of the initial shape of robots on jumping performances [29-31]. The actuation of jumping robots through explosive energy supply, favored by the adoption of soft structures, is largely studied. These robots are often equipped with multi-actuation systems and manufactured exploiting multi-material printing technologies [32-36]. Jumping robots that are actuated by external magnetic fields can achieve multi-locomotion modes and can realize fast switch [37] between different locomotion modes.

Inspired by jumping animals' performances, researchers developed jumping robots mimicking animals' strategies to achieve controllable take-off, aerial righting, and landing buffering. The continuous increment of studies focused both on jumping animals and jumping robots, as illustrated in Figure 1, highlights how the interest in understanding and accurately reproducing jumping locomotion is rapidly increasing.

In this paper, the jumping mechanisms and control strategies over the whole jumping cycle in both jumping animals and bioinspired jumping robots have been systematically reviewed, and the possible future trends of bioinspired jumping robots are predicted.

The paper is organized as follows: Section 2 presents the jumping mechanisms of invertebrate, vertebrate, and aquatic jumping animals and the corresponding bioinspired jumping robots; In Section 3 , the strategies adopted by jumping animals and robots in controlling take-off angle, direction, velocity, and stability are concluded; Section 4 compares the different strategies adopted by jumping animals and robots to achieve aerial righting; Section 5 concludes the landing buffering and resetting mechanisms 
in animals and robots; Section 6 concludes the issues to be addressed and prospects of jumping robots; Section 7 concludes the beforementioned parts and predicts the developmental trends of jumping robots inspired by the strategies adopted in jumping animals.

\section{घumping robot $\square$ jumping animal}

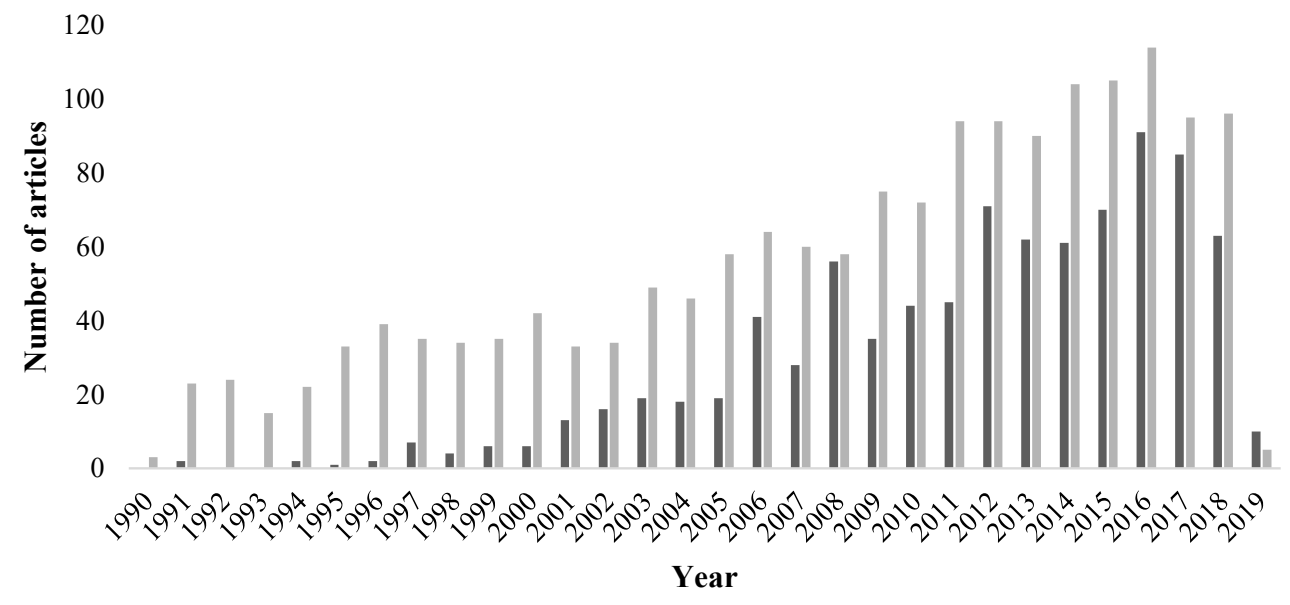

Figure 1. Number of published research items per year (1990-2019, until 20 February 2019) focusing on jumping animals and robots.

\section{Jumping Animals and Biomimetic Miniature Jumping Robots}

Jumping is an important locomotion strategy adopted by different animal species including insects, frogs, lizards, and mammals. In addition, jumping is adopted by animals living in various environments, such as plains, jungles, rainforests, ponds, and oceans. To make the structure of this review concise and simple, jumping animals have been classified into three subcategories: invertebrates, vertebrates, and animals jumping in aquatic environments (including invertebrates and vertebrates), as shown in Figures 2-4, instead, show some examples of jumping animals and jumping robotic artifacts respectively.

\section{Jumping animals}

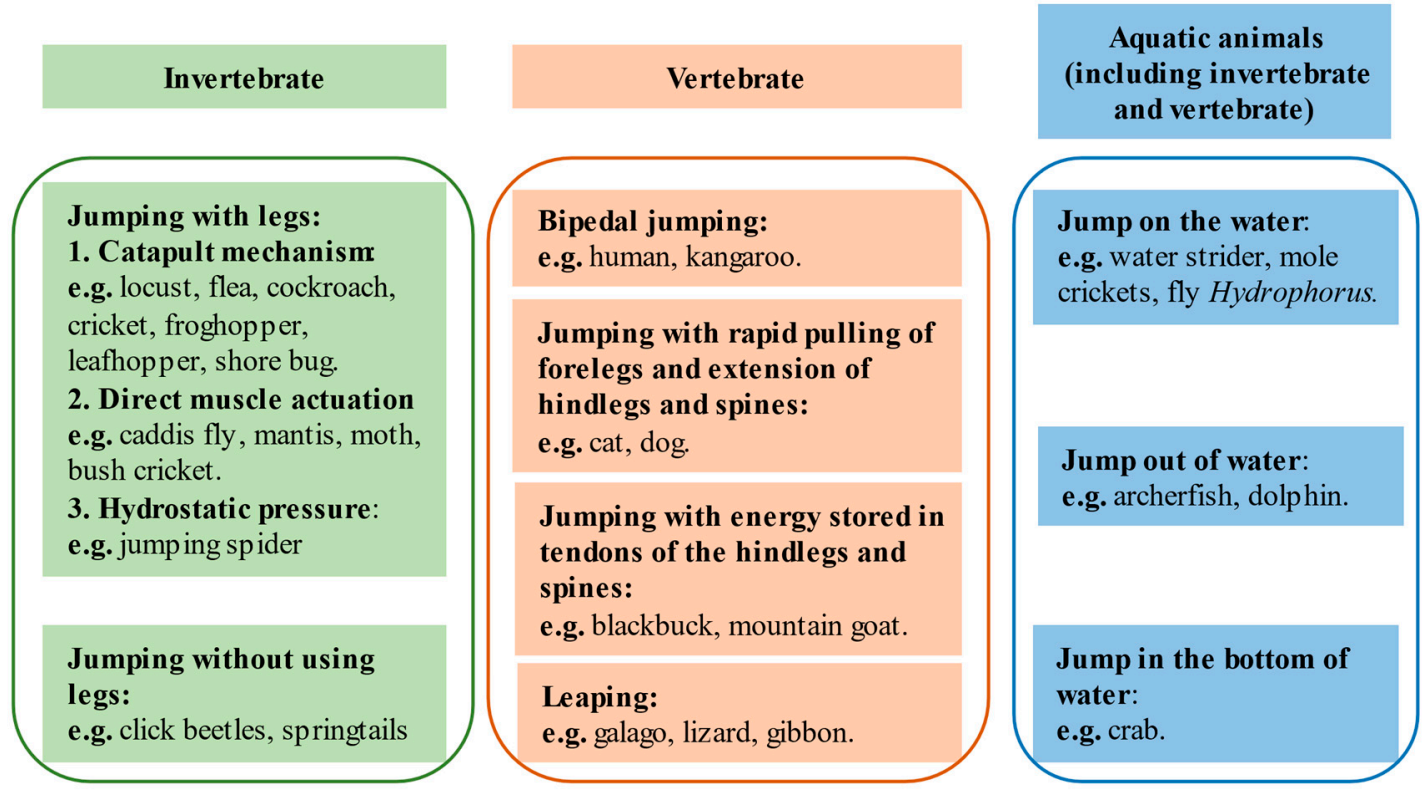

Figure 2. Classification of jumping animals in three subcategories: invertebrate, vertebrate, and aquatic jumping animals (including invertebrate and vertebrate animals). 


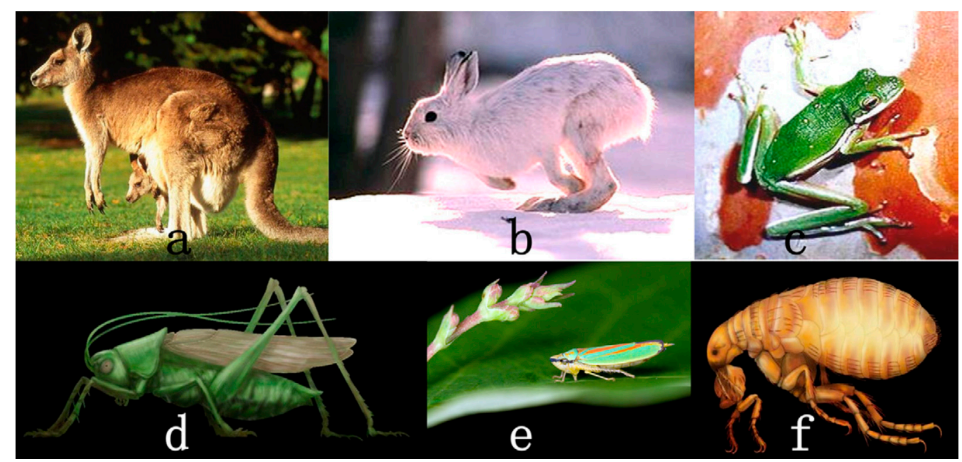

Figure 3. Jumping animals ranging with body size [38]: (a) kangaroo; (b) rabbit; (c) frog; (d) cricket; (e) leafhopper; (f) flea.

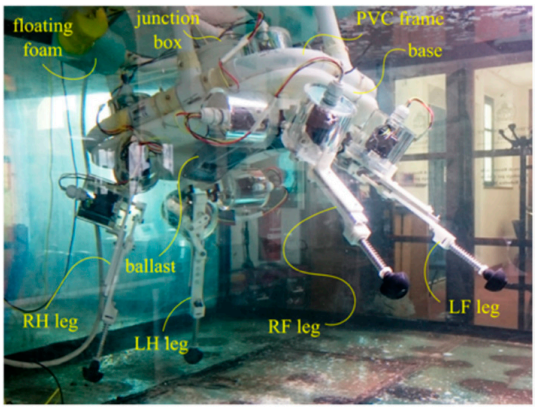

(a)

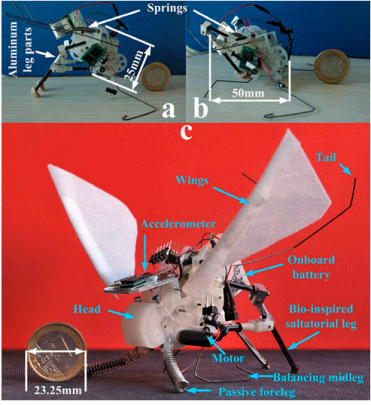

(b)

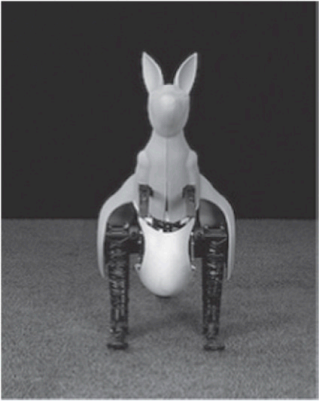

(c)

Figure 4. Examples of jumping robots: (a) Multi-legged underwater robot [39]; (b) Leafhopper-inspired jumping robot [38,40]; (c) Bionic-Kangaroo [41].

\subsection{Invertebrates}

In general, jumping strategies of invertebrate animals can be divided into [42]: (i) animals jumping without legs and (ii) animals jumping with legs. Among these latter, some jump through catapult mechanism, while the others use direct muscle actuation. An exception is represented by jump striders (Hemiptera: Gerridae), whose jumps are powered by means of hydrostatic pressure or direct muscle actuation assisted with hydraulic augmentation [43]. Invertebrate animals jumping without legs (e.g., click beetles [44] and springtails [45]), share similar energy storage/release elements in their body. Some examples are the joints between the head and body in click beetles [44] and the abdominal sclerites in springtails [45].

Catapult mechanism is much more studied than direct muscle actuation because of its more powerful jumping performances. Thus, animals jumping through catapult mechanism are largely taken as biological models to develop bioinspired jumping artefacts. In many cases, these animals use jumping in combination with other types of locomotion. For instance, insects often exploit jumping to effectively initiate flight, by providing with their hind legs the necessary trust to leave the ground and by avoiding collisions between wings and substrates. Some examples are represented by caddisflies [46], moths [47], and locusts [47].

Jumping without legs is used by click beetles [44], mainly to reset the body after falling down. This fact has inspired researchers to add an analogous resetting function to terrestrial robots, increasing their locomotion agility. Legless larvae of the genus Asphondylia (Diptera: Cecidomyiidae), fix their rear ends and move their heads to latch their bodies into a loop. After producing enough pressure, they can exhibit powerful jumps covering 30 times their body lengths [48-50]. These animals provide brilliant blueprints to build up jumping robots without legs.

Jumping performances of invertebrate animals are listed in Table 1 . The performances of existing jumping robots inspired by invertebrate animals are listed in Table 2. In the following subsections, the jumping performances and mechanisms of jumping spider, locust, flea, cricket, cockroach, froghopper, and leafhopper are introduced. In addition, the research statuses of jumping robots inspired by those invertebrate animals are compared. 
Table 1. Comparisons of tested jumping performance in invertebrate animals.

\begin{tabular}{|c|c|c|c|c|c|c|c|c|c|c|c|c|c|}
\hline Strategy & Animals & $\begin{array}{c}\text { Body } \\
\text { Length } \\
(\mathrm{mm})\end{array}$ & $\begin{array}{l}\text { Body Mass } \\
\quad(\mathrm{mg})\end{array}$ & $\begin{array}{c}\text { Take-off } \\
\text { Time } \\
(\mathrm{ms}) \mathrm{t}\end{array}$ & $\begin{array}{l}\text { Take-off } \\
\text { Angle ( }{ }^{\circ} \text { ) }\end{array}$ & $\begin{array}{l}\text { Take-off } \\
\text { Velocity } \\
(\mathrm{m} / \mathrm{s}) \mathbf{v}\end{array}$ & $\begin{array}{l}\text { Acceleration } \\
\left(\mathrm{m} / \mathrm{s}^{2}\right)\end{array}$ & $\begin{array}{c}\mathrm{a} / \mathrm{g} \\
\mathrm{g}=9.81\end{array}$ & $\begin{array}{c}\text { Energy } \\
\text { (uJ) }\end{array}$ & $\begin{array}{l}\text { Power } \\
(\mathrm{mW}) \mathrm{p}\end{array}$ & $\begin{array}{c}\text { Power/Muscle } \\
\text { Mass (w/kg) }\end{array}$ & $\begin{array}{c}\text { Ratio of } \\
\text { Leg } \\
\text { Length }\end{array}$ & $\begin{array}{l}\text { Leg } \\
\text { Ratio }^{17}\end{array}$ \\
\hline \multirow{7}{*}{$\begin{array}{l}\text { Catapult } \\
\text { mechanism }\end{array}$} & $\begin{array}{c}\text { Locust }^{1} \\
{[48,51-53]}\end{array}$ & & 70 & $25-30$ & 45 & 3.2 & 107 & 11 & 103 & $360-450$ & $51,420-64,285$ & * & * \\
\hline & Flea $^{2}[54,55]$ & $1.8 \pm 0.19$ & $0.7 \pm 0.16$ & $1.4 \pm 0.25$ & $39 \pm 5.7$ & $1.3 \pm 0.21$ & $960 \pm 233$ & $98 \pm 23.7$ & $0.6 \pm 0.28$ & $0.43 \pm 0.19$ & $6000 \pm 2100$ & 1:1.3:1.9 & 154 \\
\hline & Cockroach $^{3}$ & $6.3-10$ & 31 & $10.6 \pm 1.0$ & 40 & $1.5 \pm 0.3$ & 220 & 23 & 38 & 3.4 & 1100 & 1:1.2:2.4 & 150 \\
\hline & Cricket $^{4}[58]$ & & $700 \pm 100$ & 1.1 & * & $*$ & * & * & 820 & $30 \pm 20$ & $3800 \pm 2200$ & * & * \\
\hline & $\begin{array}{c}\text { Froghopper }{ }^{5} \\
{[59,60]}\end{array}$ & $6.1 \pm 0.08$ & $12.3 \pm 0.74$ & 0.875 & $46.8 \pm 2.0$ & 4.7 & 5400 & 550 & 136 & 155 & 126,000 & $1: 1: 1.5$ & 66 \\
\hline & $\begin{array}{c}\text { Leafhopper }{ }^{6} \\
\text { [61-63] }\end{array}$ & $9.2 \pm 0.33$ & $19 \pm 1.10$ & $6.4 \pm 0.21$ & $34.3 \pm 5.90$ & $1.2 \pm 0.13$ & 188 & 19 & 14 & 2 & 1053 & $1: 1.1: 1.9$ & 82 \\
\hline & Shore bug ${ }^{7}[64]$ & $3.5 \pm 0.09$ & $2.1 \pm 0.09$ & $3.9 \pm 0.05$ & $34 \pm 0.9$ & $1.3 \pm 0.03$ & $335 \pm 9.4$ & $34 \pm 0.9$ & $1.8 \pm 0.1$ & $0.5 \pm 0.02$ & 4500 & 1:1.2:1.8 & 89.6 \\
\hline \multirow{4}{*}{$\begin{array}{c}\text { Direct } \\
\text { muscle } \\
\text { actuation }\end{array}$} & Moth $^{8}[47]$ & $9.1 \pm 0.6$ & $5.4 \pm 0.9$ & $11.8 \pm 1.1$ & $44.4 \pm 5.1$ & $0.8 \pm 0.1$ & 71 & 7 & 1.9 & 0.2 & 299 & 1:1.4:2.1 & 132 \\
\hline & Caddisfly ${ }^{9}[46]$ & $11.4 \pm 0.3$ & $38.1 \pm 2.4$ & $15.4 \pm 0.8$ & * & $0.9 \pm 0.04$ & 57 & 6 & 16.4 & 1 & 256 & 1:1.5:1.7 & 105 \\
\hline & Mantis ${ }^{10}[42]$ & $70.7 \pm 4.0$ & $939.2 \pm 84.8$ & $65.9 \pm 2.7$ & $23.1 \pm 2.6$ & $1.12 \pm 0.03$ & 17 & 1.73 & 598.07 & 8.94 & 63.44 & 1:0.7:1.0 & 66 \\
\hline & $\begin{array}{c}\text { Bush cricket }{ }^{11} \\
{[65]}\end{array}$ & $23.2 \pm 0.8$ & $602 \pm 42$ & $\begin{array}{c}32.6 \pm \\
0.95\end{array}$ & 34 & $2.12 \pm 0.33$ & 65.03 & 6.63 & 1380 & $40(67)$ & 664 (1113) & 1:1.2:4.6 & 158 \\
\hline $\begin{array}{c}\text { Hydrostatic } \\
\text { pressure }\end{array}$ & $\begin{array}{c}\text { Jump spider } \\
\text { [66-68] }\end{array}$ & $6.1 \pm 0.3$ & $19.95 \pm 4.71$ & * & $11.4 \pm 5.2$ & $0.99 \pm 0.13$ & * & * & $10 \pm 4$ & * & * & * & * \\
\hline \multirow{3}{*}{$\begin{array}{c}\text { Jump } \\
\text { without legs }\end{array}$} & $\begin{array}{c}\text { Click beetle }^{13} \\
\text { [69-71] }\end{array}$ & $10-12$ & 40 & 0.64 & 85 & 2.4 & 3800 & 380 & 115 & 185,000 & 130 & * & * \\
\hline & Springtail $^{14}$ & 2 & 2.1 & 6.0 & * & 1.4 & 981 & 98 & 0.001 & * & $*$ & * & * \\
\hline & Larva ${ }^{15}[49,50]$ & 3 & * & * & * & 1 & 18,000 & $*$ & * & $*$ & * & * & * \\
\hline
\end{tabular}

${ }^{1}$ Schistocerca gregaria; ${ }^{2}$ Archaeopsyllus erinace; ${ }^{3}$ Saltoblattella montistabularis; ${ }^{4}$ Gryllus bimaculatus; ${ }^{5}$ Philaenus; ${ }^{6}$ Cicadella; ${ }^{7}$ Saldula saltatorial; ${ }^{8}$ Hofmannophila pseudospretella;

${ }^{9}$ Limnephilus marmoratus; ${ }^{10}$ Stagmomantis theophila; ${ }^{11}$ Pholidoptera griseoaptera; ${ }^{12}$ Sitticus pubescen Silk; ${ }^{13}$ Athous haemorrhoidalis; ${ }^{14}$ Tomocerus longicornis; ${ }^{15}$ Asphondylia, ${ }^{16}$ Front: Middle: Hind; ${ }^{17}$ Hind leg length $\%$ of body length. 


\subsubsection{Jumping Spider Inspired Jumping Robots}

The jumping spider (Araneae Salticidae) is a special case among jumping invertebrates, due to the lack of skeleton structures in its legs, and its jumping mechanism is particularly complex and differs between species. In some of them, the hydrostatic pressure could be the main energy source [68]. In others, like Phidippus regius, the muscle mass is sufficient to provide the power required for jumps [43] and, when necessary, they jump with hydraulic augmentation. An interesting feature in these spiders is that the silk is used to right the body pitch angle, in order to optimize the landing process. This aerial righting mechanism is crucial for dynamic stability and prey capture [66].

Faraji et al. proposed a spider-inspired jumping robot [73,74], which mimics the anatomy of jumping spiders [75] and whose hind legs are specifically dedicated to take-off powering, while their front legs adjust the take-off angle in the same way as locusts.

A team at the Cornell University, instead, is focusing on the design of a miniature jumping robot called "ArachnaBot" [76]. It takes inspiration from the muscles and the hydraulically augmented joints of jumping spiders: the tendon system is actuated by a motor located on the top in order to lock the joint, and the pneumatic system is used to unlock the joint suddenly when the air pressure overcomes the threshold that is set.

Another robot that takes inspiration from jumping spiders was proposed by Han et al. [77]. It is a six-leg jumping robot which can realize vertical jumps, sideway jumps, and forward jumps with preadjustment of all its six 4-DOF (Degree of Freedom) legs. Simulated results indicate that it can maintain stability and achieve multi-directional jumping. This is crucial for real applications of jumping robots.

Finally, Shield et al. focused on the aerial righting capability of jumping spiders by means of their draglines. They manufactured a robot capable to control and adjust the aerial pitch angle [78]. This robot has the advantage of being small and lightweight but the control of kinematics is not so effective because of too uncertain feedbacks.

\subsubsection{Locust Inspired Jumping Robots}

Locusts' jumping dynamics is the most investigated among jumping animals [48,79-82]. Locusts are endowed with three pairs of legs and wings. The enlarged hind legs, consisting of femur, tibiae, and tarsus [83], help these insects achieve brilliant jumping performances [79], while middle and fore legs mainly support the body weight and adjust the take-off angle and take-off direction. While middle and fore legs represent a typical walking limb, the hind legs are specialized to realize the perfect jumping and kicking in locusts [84]. The hind legs are relatively longer than middle legs and fore legs, whose femur is occupied by strong extensor muscle and relative slim flexor muscle. The extensor muscle consists of short fibers arranged in chevron blocks, while long and thin fibers make up the flexor muscle [85]. Locusts jump with catapult mechanism: through the slow contraction of the extensor muscles of hind legs, energy is stored into the fibers of the muscles themselves and into the distortions of the exoskeleton, including the two semilunar processes (SLPs) located at the end of the femur-tibiae joints.

Jumping is used as the key locomotion mode in locusts to escape from predators or initiate flying phase [85]. The jump of these insects consists of three phases: initial flexion, cocontraction, and triggering $[86,87]$. Normally in cocontraction phase, energy is stored in 300-600 ms. The specialized hind legs structure allows the small flexor to overcome the strong extensor in flexed position. The flexor of hind legs has a bigger mechanical advantage over extensor, increasing from 1.5:1 in 120 extended position to 21:1 in flexed position [85]. In contrast, this value keeps invariable, about 2:1, for middle legs. Due to the existence of a small gap between distal of tibiae and proximal of femur in hind legs, the minimum flexed angle of femur and tibiae in hind legs is almost zero, while this angle is $25^{\circ}$ in middle legs, which gives locusts the ability to jump directly upright.

Kovac et al. proposed a $7 \mathrm{~g}$ locust-inspired jumping robot [88], in which a micro motor and a four-stage gearbox are used to drive an eccentric cam that slowly loads the torsional spring located 
at the hip joint and then releases it fast. By means of the parallelogram legs, the energy stored into the torsional spring is transmitted to the foot to accelerate the robot's body. By manually adjusting the length of the foot and the take-off angle, the acceleration time and trajectories of the foot can be changed. The energy stored in the torsional spring can change in stepped variation via manually adjusting the fixed position of the torsional spring. In a second version, this robot can also adjust the take-off angle and velocity by manually coordinating the length of the foot and the fixed position of the torsional spring [89]. In its third and last version, it can realize landing buffering by means of an auxiliary carbon cage [90] or gliding wings [91-93], and azimuth control by means of an added motor that rotates the whole body around the carbon cage axis [94]. On the one hand, these auxiliary mechanisms improve the controllability of jumping, while, on the other hand, they sacrifice jumping height and distance because of the added weight: the latest version with fixed gliding wings can jump only $12 \mathrm{~cm}$ high [93].

Zaitsev et al. [95-97] developed a locust-inspired jumping robot, in which a torsional spring is located at the knee joint to mimic the important role of the semilunar process in the jumping of locusts. The femur and tibiae are designed as two carbon fiber rods of equal length, and a torsional spring is located at the knee joint. By rotating a revised servo motor, the rope contracts to store elastic energy inside the torsional spring and locks the mechanism. After that, the motor rotates in the opposite direction to release the rope; this way, the locking mechanism quickly releases the hind legs to realize a powerful jump. Theoretical calculations show that the transmission ratio of the rope-driven mechanism is about $1 / 50$, which is much higher than the transmission ratio of an eccentric cam, which is about $1 / 5 \sim 1 / 10$. A higher transmission ratio also allows a small motor to drive a torsional spring of higher stiffness: more energy is stored but the process, of course, takes longer time. Even if this robot has a better jumping performance than adult locusts, it does not have the controllability over the take-off angle, velocity, and landing. In a second version, it solves the landing with a gliding wing [98] and can change its orientation during in-air phase. Thanks to its high take-off velocity, it can still jump $1.7 \mathrm{~m}$, open the folded wing at the peak of the trajectory, and achieve a long gliding distance of $4.5 \mathrm{~m}$. In the third and last version of this robot, Weiss et al. proposed a propelled-shaped tail mechanism that helps achieve orientation adjustment during repeated jumps [99].

Truong et al., instead, designed a locust-inspired jumping robot [100], which uses a linear spring to mimic the extensor and a rope to mimic the flexor in locusts, in combination with a small DC motor, reduction gears and an eccentric cam.

Zhang et al. [101-103] have proposed two generations of locust-inspired jumping robots and carry out systematic and in-depth research on steering, resetting, and path planning of swarm jumping robots. Their first generation of locust-inspired jumping robot uses a similar eccentric cam as the robot developed by Kovac et al. [88]. The addition of a support tail enables active resetting after the robot falls down and an intermittent adjustment of the take-off direction [104]. By changing the position of the counterweight fixed into the tail end, this robot can adjust the take-off angle within a small range. Zhang et al. endowed their robotic swarm with Zigbee network technology to investigate the possibility of applying this technology to remote home monitoring $[105,106]$. Their second-generation of locust-inspired jumping robot can simultaneously perform crawling and jumping using a single motor, mainly simulating the multi-locomotion mode of locusts [102].

Finally, Chen et al. [83,107-112] conducted in-depth research on locust jumping, flapping, and land buffering mechanisms and developed a wheeled jumping robot using incomplete gear. By analyzing the recorded high-speed videos of locust landing, they established a mathematical model to study the land buffering mechanism of locusts, and they proposed a multibranch buffering leg model that provided new insight into the strategies for overcoming the limitations about landing performances of jumping robots [110]. Recently they designed a one degree of freedom (one DOF) jumping leg mechanism, which mimics the kinematic and dynamic stability during locusts' take-off phase [113]. Jumping stability is the key parameter to keep aerial stability after take-off. 


\subsubsection{Flea Inspiring Jumping Robot}

It is reported that fleas can jump over obstacles that are more than 40 times their own size, and they can execute a brilliant jump in less than one millisecond [54]. Although jumping performances vary among species [114], all jumping mechanisms of fleas are essentially very similar to each other [115-117]. First, fleas lock the two hind legs, slowly deforming their muscles as they were springs in which energy is stored; then a huge amount of power is provided to perform a brilliant jump. During take-off, their legs work as a lever system to transmit forces from the springs to the ground, passing through the tarsus [55].

Noh et al. [118] developed a flea inspired jumping robot, using three SMA springs to mimic the coordination of different muscles inside the hind legs of flea. With a $2 \mathrm{~cm}$ body length and a $1.1 \mathrm{~g}$ body weight, it can achieve a jump height around 30 times its body size. Based on this robot, the effect of legs' compliance and take-off angle on jumping efficiency are studied $[119,120]$. The team subsequently proposed another flea inspired jumping robot [121-123] that exploits bistable torque reversal mechanism. This robot can achieve a jump height of about 150 times its own body size with a body mass of $30 \mathrm{mg}$.

Ackerman, in collaboration with Boston dynamics, developed jumping robots using explosive energy, such as "Urban Hopper" [124] and "SandFlea" [125]. "SandFlea" can freely adjust the take-off angle, height, and distance. The explosion energy helps "SandFlea" achieve a jumping height of $10 \mathrm{~m}$. The jumping height can be adjusted according to the size of the obstacles, and it is possible to execute a maximum of 25 consecutive jumps. However, it is unable to realize aerial righting.

\subsubsection{Cricket Inspired Jumping Robots}

Crickets are good at jumping thanks to their strong hind legs [58]. Calculated results show that they can jump with a specific power, around ten times more than locust's muscle system can generate $(3.8 \mathrm{~W} / \mathrm{g}$ versus $0.45 \mathrm{~W} / \mathrm{g})$. This could indicate that crickets use an energy-storage and quick-release mechanism like locusts, although experimental results rather suggest that it could be a special case of cocontraction without electrical coactivation [58].

Based on the fast crawling and jumping mechanism of the cockroach, Laksanacharoen et al. [126-128] proposed a pneumatically driven cricket-inspired robot, able both to crawl and jump. It can achieve short distance jumps. To improve the agility of locomotion, a wheeled cricket jumping robot was proposed later $[129,130]$, endowed with a special three-claw wheel meant to mimic the strategy that crickets use to overcome obstacles, i.e., raising the body inclination. This greatly improves the ability of the robot to overcome obstacles.

\subsubsection{Cockroach Inspired Jumping Robots}

Cockroaches are famous for their fast locomotion and their excellent surviving abilities in confined environments, thanks to a soft body capable of very effective shape-changing. This provided biological inspiration for the development of a soft, legged robot dedicated to search and rescue activities in unstructured and dangerous environments, like earthquakes or explosions [131].

Cockroaches also own fast crawling abilities and some species are able to jump [56,57]. The large hind legs have grooved femora, into which the tibiae engage fully before a jump is performed. Resilin, which is an elastic protein located at the femur-tibiae joint of hind legs, works like the semilunar processes in locusts. In experiments, the extensor muscles contracted for $224 \mathrm{~ms}$ before the hind legs moved, indicating that energy is first stored into the muscles' deformation and then released suddenly in a catapult action to propel a powerful jump [56].

Harvard University recently proposed a cockroach-inspired crawling and jumping robot, called "HAMR" [132], that represents the first attempt to design and actuate a robot with a body size at centimeter-level. The four legs of this robot share the same structures, and two piezoelectric actuators can help each leg realize agile space movements. This robot, with body length of $4.5 \mathrm{~cm}$ and body mass of $2.8 \mathrm{~g}$, can achieve crawling with a speed of $17.2 \mathrm{~cm} / \mathrm{s}$, jumping, climbing, and sharp turning through 
four-leg coordinated control. "HAMR" is light and compliant, and it is first built in a planar sheet and then popped out in its 3D structure. It can take some payload and fall from a certain height without structural damage. In its later version [133], this robot can swim and walk underwater, and also float on the water exploiting surface tension.

\subsubsection{Froghopper Inspired Jumping Robots}

Froghoppers have a ventral protrusion from a coxa, which engages with a protrusion from the dorsal surface of the femur. This means that both hind legs are held in fully cocked position without moving for a few seconds. At some point, hind legs depress and extend completely in less than $1 \mathrm{~ms}$ and a click sound occurs at the start of a jump, which possibly originates from the initial movements of the coxo-trochanteral joint or from the disengagement of the coxa and femur [61,62].

Sutton et al. [134] found that, during jump, froghoppers can control the take-off angle by adjusting the relative positions of hind legs' tibiae, realizing synchronous jumps. Based on this, Jung et al. proposed a froghopper-inspired robot with adjustable take-off direction [135] by means of a gear mechanism placed at the hip joints of hind legs. In particular, by manually acting on these gears, it is possible to preadjust the knee joint angles to achieve the controllability of take-off direction. Although these knee joints cannot be adjusted actively, this solution provides a new bioinspired idea to solve the control of the jumping direction of miniature jumping robots.

\subsubsection{Leafhopper Inspired Jumping Robots}

The hind coxae of leafhoppers are huge and are connected to each other at the midline by means of a protrusion from one coxa that inserts in a socket of the other coxa and acts like a snap closure. Its function is not sure, as larvae do not have this structure, and they can jump anyway. In leafhoppers, the fast and simultaneous depression of the trochantera around the coxae of hind legs are the key joint movements to power a jump. Cocontraction could result in storage of energy in skeletal structures in the thorax. The body asset is initially determined by the front and middle legs, and take-off is powered by the hind legs. In some jumps, the front and middle legs may contribute to the thrust during take-off, but they always loose contact with the ground a few milliseconds before the hind legs, thus their contribution to take-off is limited [61,62].

Bonsignori et al. used a high-speed camera to record the jumping of leafhoppers. By tracking and analyzing the recorded videos, they found that leafhoppers maintain a constant acceleration during take-off. Based on this findings, three generations of leafhopper-inspired jumping robots [136-138] have been proposed proposed. In particular, "Grillo-II" is the first application of eccentric cam in jumping robots and "Grillo-III" can mimic the constant acceleration characteristic during take-off by optimizing its four-bar mechanism. By adding fixed wings, the robot could land stably and jump again. At the moment the jumping height and distance of "Grillo III" are relatively low compared to the body length [38].

\subsection{Vertebrates}

The jumping mechanisms of vertebrates are classified into four groups: (i) bipedal jumping; (ii) jumping with rapid pulling of forelegs and extension of hindlegs and spines; (iii) jumping with energy stored in tendons of the hindlegs and spines; (iv) leaping, as shown in Figure 2.

Kangaroos are the most famous bipedal jumping animals and they can jump at a speed of $70 \mathrm{~km} / \mathrm{h}$ for two hours [6]. They use their long and heavy tail to control balance and propulsion, and exploit their long elastic tendons in legs to store energy that is then suddenly released to catapult themselves into the next jump.

Instead, animals like cats, dogs, and snow leopards, perform jumping mainly through rapid pulling of the forelegs and extension of the spine and hind legs; in addition, the flexion of their feet, leg joints, and spines play an important role in absorbing the shock of impact in landing phase [6].Blackbuck uses elastic energy, stored in the long tendons of the leg and in the spine, to catapult it into the next jump [6]. 
Leaping is the characteristic locomotion mode of several species of primates including forest-dwelling lemurs and bush babies (galagoes). Typically, leaping is performed by animals in trees to move from branch to branch or trunk to trunk. Leapers tend to have relatively long hind limbs and a long, flexible spine. Propulsion mainly originates from the extension of the hind legs and spine, while landing is realized by means of the forelimbs. In the leaping of lizards, tails have proved to play an important role in aerial righting after take-off.

In this part, the jumping mechanisms of vertebrate animals, including frog, galago, kangaroo, human, and dog, are discussed and the research statuses of the corresponding inspired jumping robots are concluded.

\subsubsection{Frog Inspired Jumping Robots}

Marsh et al. studied the jump performance of five different kinds of bull frogs [139]. The measured muscle-mass-specific power ranges from $225 \mathrm{~W} / \mathrm{kg}$ to $1000 \mathrm{~W} / \mathrm{kg}$, exceeding with large margin the power available from direct muscle contraction. This could be due to a redistribution of power during take-off, obtained by means of elastic energy storage, that permits to produce the power peak in the exact instant that is required. Recently, researchers demonstrated the existence of the catapult mechanism in frogs' jumping [140-142] by using high-speed marker-based biplanar X-ray cinefluoroscopy. In fact, they observed the two principal characteristics of catapult mechanism, i.e., the contraction of muscles prior to joint movements (during tendon stretch) and the rapid joint movement during tendon recoils that gives power to take-off.

Zhong et al. $[143,144]$ proposed an equivalent six-bar mechanism model for frogs' jump, manufacturing an open chain jumping robot moved by serval pneumatic muscle actuators. They applied an adaptive cascade controller to the proposed robot. This jumping robot has the capacity to jump following a desired trajectory based on optimized results. Fiorini et al. developed three generations of hopping robots for celestial exploration $[145,146]$. The second generation "Frogbot" used a six-bar geared mechanism to turn the linear spring force into a nonlinear contacting force. In their third generation of jumping robots, the take-off angle adjustment, self-righting and steering ability are also achieved. The six-bar gear mechanism is widely adopted in jumping robots [147-153] to achieve desired contact force profile and to avoid premature jumping.

\subsubsection{Galago (Baby Monkey) Inspired Jumping Robots}

Galago can execute spectacular jumps. A $0.25 \mathrm{~kg}$ galago can execute $2.25 \mathrm{~m}$ vertical jumps, which means that the displacement of the centroid during the flight phase is approximately six body lengths (tail not included). The muscles of the hind limbs of the galagoes account for $25 \%$ of the entire body weight and produce powerful propulsion. The peak power output calculated during take-off is around $2200 \mathrm{~W} / \mathrm{kg}$, and this value is much higher than that of the tested power output of muscle fiber bundles in animals, around $1000 \mathrm{~W} / \mathrm{kg}$ [154-156]. Peaks in power output likely imply elastic recoil of the complex aponeurotic system of the vastus muscle, which works as a mechanical power amplifier. Mechanical power amplification means that elastic strain energy is stored during the initial phase of jumping, to be then released at an increased rate during take-off.

Haldane et al. recently proposed the galago-inspired jumping robot "Salto" [157,158]. Through the optimization of the multi-linkage parameters [159], the obtained eight-bar mechanism can achieve a series of requirements: (i) the foot trajectory can always be kept in a vertical line; (ii) due to zero momentum, the trajectory of the center of mass is not deflected during the jump; (iii) the ground contact force is always maintained at a constant value by considering the series of elastic actuators. "Salto" can realize pitch angle righting using an inertial tail and can perform the parkour similar to humans. Vertical jumping agility is a new proposed concept and is measured by vertical distance per second, corresponding to the average vertical speed that a system can attain with repeated jumps. This parameter is very important in natural environments, since it decides how quickly a predator can catch its preys or how quickly a prey can escape from its predators. "Salto" is the most agile 
jumping robot ever built. The improved version, "Salto-1P", $[160,161]$ can perform controlled yawing and rolling movements of the body using two propellers and an inertial tail and can perform precise continuous jumping. During the design of "Salto" series jumping robots, researchers focused mainly on the similarity of the jumping mechanism and performance with real animals.

\subsubsection{Kangaroo-Inspired Jumping Robots}

Hopping technique is quite widespread among jumping vertebrates. In Australia, hopping has evolved both in the macropods (kangaroos, wallabies, and bettongs) and in hopping mice [162]. Outside of Australia, the biggest mammals which do hopping are springhares in Africa and lemurs. McGowan et al. [163] compared five groups of mammals that evolved bipedal hopping independently from each other, and proposed that bipedal hopping evolution is associated with predator avoidance by relatively small species in forest environments.

As regards hopping of kangaroos, in the low velocity range the oxygen consumption increases as velocity increases, while it shows a slightly decreasing trend in the high velocity range. This means that high speed hopping is an efficient locomotion mode for kangaroos [164]. This is probably due to the exceptional elastic energy storage and recovery via long compliant tendons in the kangaroos' legs $[8,165]$. The highest locomotion velocity in kangaroos are remarkably correlated to the body mass [166].

The German robotics company Festo developed "BionicKangaroo" [41,167]. It exploits an elastic spring that mimics the biological leg tendons to efficiently recover energy from one jump and to release it for powering the next jump. It can jump $0.4 \mathrm{~m}$ vertically and $0.8 \mathrm{~m}$ horizontally, with $7 \mathrm{~kg}$ body weight and $1 \mathrm{~m}$ body height. Nonlinear controllers are designed for the flight and stance phases [41]. The tail is used to compensate the torque created at the hip joint.

Liu et al. $[168,169]$ developed another kangaroo-inspired jumping robot. The locomotion of the Center of Mass (CoM) of the robot is based on the reduced-order Rolling Spring Loaded Inverted Pendulum (R-SLIP) model and an active tail is equipped for aerial righting. Compared to stationary tail and active tail with open-loop control, the experimental results show that active tail with closed-loop control can achieve much better aerial righting performance during flight.

Another remarkable kangaroo-inspired jumping robot was developed by Jun et al. [170]. It uses a four-bar mechanism and an eccentric cam to achieve intermittent jumping. The tail is used both in aerial righting and landing buffering.

\subsubsection{Human-Inspired Jumping Robots}

Human jumping mainly relies on the coordination of nine muscle-tendon actuators during force generation [171].

Niiyama et al. [172-174] developed a biped jumping robot with an artificial musculoskeletal system, which consists of six McKibben pneumatic muscle actuators used to actuate hip, knee, and ankle joints. It can achieve a height more than $50 \%$ of body height, which is remarkable for a multiple-DOF legged robot, and land softly from $1.0 \mathrm{~m}$ drop off. This work provides blueprints for the design of musculoskeletal robots.

The robotics company Boston Dynamics released new videos $[175,176]$ of the Atlas robot, and this human inspired robot can jump over a log, hop up a series of platforms, do parkour, and perform a backflip.

\subsubsection{Dog-Inspired Jumping Robots}

In the jumping of dogs, the forelimb works as an important balancer and hind limb works as a propeller.

Hyon et al. $[177,178]$ developed a dog-inspired jumping robot "KenKen". There are two active joints, including hip and knee joints, and a passive ankle joint. A linear spring is attached between the thigh and heel parallel to the shank to mimic the role of the tendon. It works as one part of the parallel four-bar linkage during flight phase, absorbs some shock during landing, and reuses the restored energy for next jump. 


\subsection{Specialized Jumping Performance: Aquatic Environments}

Aquatic environment is a new area for jumping robots to survive. There are some animals skilled at jumping in aquatic environments, such as water striders [179], mole crickets [180], flies Hydrophorus [181], which can jump on water; archer fishes [182] and dolphins can jump out of water in order to communicate or catch preys; and crabs [183] have a very special locomotion mode, named "punting" in the bottom of water.

For animals jumping on water, a lot of different strategies exist. Small size creatures, like water strider, use their superhydrophobic hind and middle legs [179] to exploit surface tension and generate thrust. In flies' take-off, the use of both jumping and flapping increases the take-off velocity and decreases the take-off time with respect to take-off only relying on flapping from the water surface. They jump relying on the direct actuation of middle legs and hind legs without penetrating the water surface and make use of the surface tension of water [181]. Meanwhile, big size animals, like frogs [184] and basilisk lizards [185-187], also use the surface tension to run on water by generating a turbulent flow beneath their wide and flat feet. Basilisk lizards have to maintain a pocket above their feet. Mole crickets and copepods exploit water viscosity to jump. In pygmy mole crickets, jumping is powered by rapid extension of the hind tibiae as other orthopteran insects [188]. In addition to the excellent jumping performances on the ground, they can also jump on water [180]. Thanks to a unique array of spring-loaded paddles and spurs that increase the contact area, pygmy mole crickets move their powerful hind legs so quickly that they penetrate the surface as they move through the water. Catapult mechanism is used to move the tibiae very quickly to generate big forces through a laminar flow of water beneath hind tibiae.

Animals that can jump out of water adopt different strategies. Famous jumpers like dolphins accelerate their bodies from the bottom of the water and use the accumulated momentum when they arrive at the water surface to break the water. Archer fishes use a gentler way, and they can generate thrust from a still position close to the water surface, jumping out of water. In addition to the use of shooting, they also exploit jumping to catch preys [189], mainly when several fish are gathered together and the situation is more competitive $[182,190]$. Through kinematics and hydrodynamics analysis of archerfish jumping, Techet et al. found that archer fishes use their tail in combination with anal, pectoral, and dorsal fins to generate enough thrust from still position in order to jump out of water, and they also want to design an archer fish-inspired robot that can jump smoothly from water.

Some animals adopt leg locomotion to move in the bottom of water; for example, crab, octopus, and lobster. A new locomotion mode adopted by crab, which is named "punting", has been discovered and gave inspirations to researchers to design a new generation of underwater vehicles that use legs to move [183].

In this part, the jumping mechanisms and performances of aquatic animals, including water-strider, dolphin, and crab, are introduced. In addition, the research statuses of the corresponding bioinspired jumping robots are reviewed.

\subsubsection{Water-Strider Inspired Jumping Robots}

Water-strider is one kind of small insect commonly found in lakes, ponds, paddy fields, and wetlands. It can walk, glide, and jump on water surface. Researchers have conducted thoroughly studies on the floating and locomotion mechanism of water-strider. The results show that the agile locomotion ability of water-strider on the water surface is mainly due to the superhydrophobicity [191,192] of its own leg structure, capable to provide enough surface tension. Water-strider can increase the support force by increasing the depth of the leg into the water [179]. By moving their superhydrophobic hind and middle legs inward at a relatively low descending velocity, water striders can generate a force that is below the value required to break the water surface and initiate jumping [179].

Researchers from Seoul National University and Harvard University collaboratively developed a microscale water strider-inspired skating robot [193] and another jumping robot based on SMA and bistable click mechanism [194] that, in its latest version [179], has a mass of only $68 \mathrm{mg}$ and astonishing performances: $1.6 \mathrm{~m} / \mathrm{s}$ take-off velocity, $142 \mathrm{~mm}$ jumping height. The size of the robot, the locomotion mechanism, and the trend of the contact force during take-off are very similar to 
water-strider [179]. At the same time, researchers used a high-speed camera to study the jumping mechanism of water-strider. Recordings were used to establish a mathematical model that allows to calculate the support force during take-off. It was found that water-strider can get maximum momentum by moving the four legs, without destroying the water surface.

Feng et al. [191,192] analyzed the microscopic mechanism of superhydrophobic materials and the locomotion mechanism of the water-strider, which lays a foundation for the development of the subsequent water-strider walking robots [195] and jumping robots $[196,197]$. Their water-strider-inspired jumping robot $[196,197]$ combines support legs and propulsive legs. This is achieved by means of a click mechanism using incomplete gears. Through simulations and experiments, the effects of the foot area, spring stiffness, and take-off angle on the take-off performance of the robot have been studied. The robot can make use of the buoyancy achieved by superhydrophobic nickel foam materials, that, among others, reduce energy consumption. The possibility of applying water strider-inspired robots to water quality surveillance and water pollution monitoring is also mentioned [195].

Jiang et al. [198] developed a water-strider-inspired jumping robot that uses incomplete gears and ropes to drive a carbon fiber elastic band. It can realize jumping by rapid kicking of feet. The minimum body weight of the robot is achieved by optimization of the mechanism and the jumping performance is predicted based on a general and simplified mathematical model proposed. In the experiments, the jumping height is less than the robot leg's length. An integrated optimization combining the mechanism optimization and the jumping modelling is required to improve the jumping performance in the future.

\subsubsection{Dolphin-Inspired Jumping Robots}

The entire leaping process is divided into five phases: (i) acceleration phase; (ii) surfacing phase; (iii) take-off phase; (iv) flight phase; (v) diving phase [199]. Dolphins generate large thrust when swimming at almost constant depth in acceleration phase. This is the key reason why dolphins can leap out of water.

Researchers at the Cornell University studied the strategies that aquatic animals, like tiny crustaceans and huge dolphins, use to leap out of the water. They developed a simple robot that uses catapult mechanism inspired by animals to investigate the important parameters in the "water entry and exit" behavior of animals. They concluded that the streamlined body shape is very important because the designed robot takes too much water after leaping out of water [200]. In addition, the click mechanism used by this inelegant robot to leap out of water is rare to see in aquatic animals.

Yu et al. modeled the leaping of dolphins and found that the main important parameters are the muscle power and the streamline body shape [199]. Based on this, they developed a dolphin-inspired jumping robot, which emphasizes the powerful tail and streamlined body; meanwhile they developed active leaping control methods for a self-propelled, fast-moving dolphin robot [201]. The proposed dolphin robot can leap with a velocity of 2.3 body length per second and it jumps out of water with angle ranging from $35^{\circ}$ to $60^{\circ}$. Meanwhile, this robot can be applied to explore and monitor the environment around the water.

In addition, studies developed robots that jump out of water with combustion gas source [202-205].

\subsubsection{Crab Inspired Jumping Robots}

With lower comparative gravity force as a result of buoyant force and longer contact time than motion on the ground, crabs use a new locomotion mode which is named "punting" [183] to effectively move on the seabed.

Inspired by the "punting" of crabs, researchers designed legged hopping robots based on the underwater spring-loaded inverted pendulum (USLIP) model [206,207]. The unique proposed underwater stabilized hopping robot "SILVER" is a new versatile alternative to explore the seabed.

\section{Controllability of Take-Off in Jumping Animals and Robots}

In the eternal struggle for survival between predators and prey, complex locomotion strategies have been developed, among which jumping plays an important role $[163,208,209]$. In this regard, 
the ability to effectively control the jump is of utmost vital importance. In particular, the controllability over take-off is much strategic and it includes the control over take-off angle, take-off direction, take-off velocity, and take-off stability. The take-off stability is strongly connected to the aerial righting strategies adopted. In this part, the control strategies during take-off phase both in jumping animals and jumping robots are concluded and compared.

\subsection{Take-off Angle}

Overall, animals have excellent ability to control the take-off angle, but there are some special issues. Due to the their morphological constraints, click beetles can only jump with a constant take-off angle $\left(79.9^{\circ} \pm 1.56^{\circ}, n=9\right.$ beetles) that directs $98 \%$ of the jumping force vertically against gravity [44]. So, click beetles are able to adjust the take-off velocity but they cannot control the take-off angle.

Locusts, instead, can adjust the take-off angle by acting on the initial position of hind legs: the angle of elevation is equal to the slope of the line drawn from the distal end of the tibia through the proximal end of the femur, and it is not affected if the two hind legs extend asynchronously [210].

Most miniature jumping robots cannot adjust the take-off angle automatically. For example, the $7 \mathrm{~g}$ locust-inspired jumping robot developed by Kovac et al. [88] and the variable gear transmission ratio kangaroo-inspired jumping robot proposed by Chai et al. [211] use the variation of the feet bar length and gear transmission ratio separately to adjust the take-off angle within a certain range. These robots have to be reassembled manually to change their mechanism parameters. The first generation of locust-inspired jumping robots proposed by Zhang et al. can adjust the take-off angle within a small range by adjusting the mass center position through the counterpart fixed on an added tail [101]. Only the third generation of jumping robots proposed by Fiorini et al. [145] can realize the adjustment of take-off angle within a wide range. The angle of the six-bar jumping mechanism relative to the ground can be adjusted acting on the position of the support leg [146].

\subsection{Take-off Direction}

Azimuth control is very important in animals' escape behavior [208,209]. Locusts can adjust the take-off direction by flexing the foreleg that is ipsilateral to the first jump direction and then extending the contralateral foreleg during the hind legs' flexion [212,213]. The take-off angle and take-off direction are controlled using two independent mechanisms, which allow the minimum change in take-off direction after the hindlegs are flexed. Froghoppers control their azimuth by changing the initial orientation of the hind tibiae; the mean angle relative to the midline can be used to predict the take-off direction [134]. This strategy is also adopted by roboticists in jumping robots design [135].

The direction of jumping robots is controlled mainly through an added mechanism and only a few jumping robots can adjust the jumping direction. To adjust the jumping direction, Kovac et al. fixed the developed jumping mechanism inside the carbon fiber and used another motor to rotate the jumping part around the axis of the carbon fiber frame. This mechanism helps the robot realize continuous adjustment of the jumping direction [94]. The locust-inspired jumping robot proposed by Zhang et al. [104] can rotate the jumping mechanism using the tail bar as a crank. By rotating the jumping part around the fix end of the tail bar just once, the robot can achieve a body rotation of $24^{\circ}$. The froghopper-inspired jumping robot proposed by Jung et al. [135] can adjust the jumping direction within a certain range by manually changing the knee joints angles of hindlegs. The third-generation of jumping robots proposed by Fiorini et al. [145] uses differential wheels to achieve adjustment of the jumping direction. This is the most popular strategy, also adopted by other wheeled jumping robots to control the jumping direction $[34,214,215]$.

In the latest version of TAUB jumping robot, propeller-shaped tail mechanism is added to realize orientation adjustment after landing [98]. 
Table 2. Performance comparisons of existing invertebrate animals inspired jumping robots.

\begin{tabular}{|c|c|c|c|c|c|c|c|c|}
\hline Year & Name & Mass & $\begin{array}{l}\text { Jumping } \\
\text { Distance }\end{array}$ & $\begin{array}{c}\text { Jumping } \\
\text { Height }\end{array}$ & $\begin{array}{l}\text { Actuators and } \\
\text { Energy Storages }\end{array}$ & Highlights & Deficiencies & Aut $^{1}$ \\
\hline 2020 & TAUB [99] & $43-46 \mathrm{~g}$ & N/A & $80-120 \mathrm{~cm}$ & Torsional spring & $\begin{array}{l}\text { Single actuator, perform the flipping } \\
\text { task after landing, reorient and jump } \\
\text { in required direction }\end{array}$ & $\begin{array}{l}\text { Jumping performance } \\
\text { is decreased because } \\
\text { of the added } \\
\text { mechanism }\end{array}$ & Y \\
\hline 2017 & Arachnabot [76] & $36 \mathrm{~g}$ & N/A & $11.5 \mathrm{~cm}$ & Fluidic air pressure & $\begin{array}{l}\text { Pneumatics and electrically-actuated } \\
\text { tendons capable of strong, dynamic, } \\
\text { and rapid joint movement }\end{array}$ & $\begin{array}{l}\text { Cannot control in air } \\
\text { posture, landing, and } \\
\text { re-jumping }\end{array}$ & $\mathrm{N}$ \\
\hline 2017 & Salto-1P $[160,161]$ & $98 \mathrm{~g}$ & $>2 \mathrm{~m}$ & $125 \mathrm{~cm}$ & $\begin{array}{l}\text { Torsional spring, } \\
\text { thruster }\end{array}$ & $\begin{array}{l}\text { Light weight, continuous jumping, } \\
\text { high agility }\end{array}$ & $\begin{array}{l}\text { No intermittent } \\
\text { jumping, limited } \\
\text { distance of wireless } \\
\text { communication }\end{array}$ & Y \\
\hline 2016 & Salto [158] & $100 \mathrm{~g}$ & N/A & $120 \mathrm{~cm}$ & Torsional spring & $\begin{array}{l}\text { Light weight, two-stage jump for } \\
\text { increased height, high agility }\end{array}$ & $\begin{array}{l}\text { Need of artificial } \\
\text { assistance, not able to } \\
\text { jump forward }\end{array}$ & $\mathrm{N}$ \\
\hline 2016 & $\begin{array}{l}\text { Froghopper-inspired } \\
\text { robot [135] }\end{array}$ & $3.06 \mathrm{~g}$ & N/A & N/A & $\begin{array}{l}\text { SMA spring and } \\
\text { linear spring }\end{array}$ & $\begin{array}{l}\text { Added gears help realize synchronous } \\
\text { jumping and change direction from } \\
\qquad-40^{\circ} \text { to } 40^{\circ}\end{array}$ & $\begin{array}{l}\text { Cannot control in air } \\
\text { posture, landing, and } \\
\text { re-jumping }\end{array}$ & $\mathrm{N}$ \\
\hline 2016 & JumpRoACH [148] & $59.4 \mathrm{~g}$ & N/A & $1.1-1.62 \mathrm{~m}$ & Latex rubber & $\begin{array}{c}\text { Adjust both crawling speed and } \\
\text { jumping take-off speed, } \\
\text { height-adjustable via a novel } \\
\text { active trigger }\end{array}$ & $\begin{array}{l}\text { Landing and resetting } \\
\text { abilities are poor }\end{array}$ & $\mathrm{N}$ \\
\hline 2015 & $\begin{array}{l}\text { Roly-poly Soft } \\
\text { Robot [36] }\end{array}$ & $2.1 \mathrm{~kg}$ & N/A & $20 \mathrm{~cm}$ & Combustion & Soft material, combustion drive & $\begin{array}{l}\text { Hard control on } \\
\text { jumping direction, } \\
\text { low jumping } \\
\text { frequency }\end{array}$ & Y \\
\hline 2014 & MultiMo-Bat [151] & $115.6 \mathrm{~g}$ & $232 \mathrm{~cm}$ & $305 \mathrm{~cm}$ & $\begin{array}{l}\text { SMA wire, cable, } \\
\text { clutch, linear spring }\end{array}$ & $\begin{array}{l}\text { High jumping distance and height, } \\
\text { components sharing, jumping } \\
\text { with gliding }\end{array}$ & $\begin{array}{l}\text { Impossibility to } \\
\text { change take-off angle, } \\
\text { lack of glide control } \\
\text { and wings regulation }\end{array}$ & $\mathrm{N}$ \\
\hline 2013 & MSU-tailbot [215] & $26.5 \mathrm{~g}$ & $90 \mathrm{~cm}$ & $87 \mathrm{~cm}$ & Spring & $\begin{array}{l}\text { Wheel on the ground, control its body } \\
\text { angle using an active tail to } \\
\text { dynamically maneuver in midair for } \\
\text { safe landings }\end{array}$ & $\begin{array}{l}\text { Impossibility to } \\
\text { change take-off angle } \\
\text { and direction }\end{array}$ & Y \\
\hline
\end{tabular}


Table 2. Cont

\begin{tabular}{|c|c|c|c|c|c|c|c|c|}
\hline Year & Name & Mass & $\begin{array}{l}\text { Jumping } \\
\text { Distance }\end{array}$ & $\begin{array}{l}\text { Jumping } \\
\text { Height }\end{array}$ & $\begin{array}{l}\text { Actuators and } \\
\text { Energy Storages }\end{array}$ & Highlights & Deficiencies & Aut $^{1}$ \\
\hline 2013 & $\begin{array}{l}\text { Jumping Robotic } \\
\text { Insect [121] }\end{array}$ & $34 \mathrm{mg}$ & N/A & $30 \mathrm{~cm}$ & SMA actuators & $\begin{array}{l}\text { Novel pop-up book MEMS process } \\
\text { may eliminate the onerous assembly } \\
\text { task caused by mesoscale components }\end{array}$ & $\begin{array}{l}\text { Integrated untethered } \\
\text { power is a } \\
\text { challenging issue, } \\
\text { cannot realize } \\
\text { multiple jumping }\end{array}$ & $\mathrm{N}$ \\
\hline 2013 & MSU-Jumper [214] & $23.5 \mathrm{~g}$ & $90 \mathrm{~cm}$ & $87 \mathrm{~cm}$ & $\begin{array}{l}\text { Cable, rotation link, } \\
\text { torsional spring }\end{array}$ & $\begin{array}{l}\text { Light weight, minimum actuation, } \\
\text { continuous steerable jumping }\end{array}$ & $\begin{array}{l}\text { Attitude stabilization, } \\
\text { no landing control }\end{array}$ & Y \\
\hline 2013 & HAMR [132] & $2.8 \mathrm{~g}$ & N/A & N/A & $\begin{array}{l}\text { piezoelectric } \\
\text { actuators }\end{array}$ & $\begin{array}{l}\text { Pop-up microelectromechanical } \\
\text { systems (MEMS) fabrication process }\end{array}$ & $\begin{array}{l}\text { Energy not on board, } \\
\text { jumping height is } \\
\text { relatively low }\end{array}$ & $\mathrm{N}$ \\
\hline 2012 & $\begin{array}{l}\text { Locust-Inspired } \\
\text { [100] }\end{array}$ & $7 \mathrm{~g}$ & $100 \mathrm{~cm}$ & $71 \mathrm{~cm}$ & Linear spring & $\begin{array}{l}\text { Mimic using springs and wire, springs } \\
\text { for passive extensor muscles, and a } \\
\text { wire as a flexor muscle }\end{array}$ & $\begin{array}{l}\text { The in-air and } \\
\text { landing are not } \\
\text { considered, lack of } \\
\text { autonomy }\end{array}$ & $\mathrm{N}$ \\
\hline 2012 & GRILLO-III [38] & $22 \mathrm{~g}$ & $20 \mathrm{~cm}$ & $10 \mathrm{~cm}$ & Linear spring & $\begin{array}{l}\text { continuous jumping, model-based } \\
\text { jumping force optimization }\end{array}$ & $\begin{array}{l}\text { Incomplete control } \\
\text { systems, lack of } \\
\text { autonomy }\end{array}$ & $\mathrm{N}$ \\
\hline 2011 & EPFL $[92,93]$ & $16.5 \mathrm{~g}$ & $30.2 \mathrm{~cm}$ & $12 \mathrm{~cm}$ & $\begin{array}{l}\text { Torsional spring, } \\
\text { cam }\end{array}$ & $\begin{array}{l}\text { Infrared remote control, reduced } \\
\text { impact force, jumping with gliding, } \\
\text { high gliding distance }\end{array}$ & $\begin{array}{l}\text { No pitch control, } \\
\text { ineffective gliding } \\
\text { when jumping from } \\
\text { the ground }\end{array}$ & $\mathrm{N}$ \\
\hline 2010 & Buckling [24] & $18 \mathrm{~g}$ & $95 \mathrm{~cm}$ & $15 \mathrm{~cm}$ & Elastic strip, snap & $\begin{array}{l}\text { Elastic energy from bending and } \\
\text { twisting, high impulsive } \\
\text { force frequency }\end{array}$ & $\begin{array}{l}\text { Need of external } \\
\text { power supply, } \\
\text { incomplete } \\
\text { synchronization } \\
\text { control }\end{array}$ & $\mathrm{N}$ \\
\hline 2009 & Sand Flea [125] & N/A & 1 & $9 \mathrm{~m}$ & $\mathrm{CO}_{2}$ & $\begin{array}{l}\text { Astonishing jumping performance and } \\
\text { make } 25 \text { jumps }\end{array}$ & $\begin{array}{l}\text { A haphazard aerial } \\
\text { tumble would } \\
\text { preclude it to send } \\
\text { back useful video } \\
\text { while in midair }\end{array}$ & Y \\
\hline 2008 & 7 g Miniature [88] & $7 \mathrm{~g}$ & N/A & $138 \mathrm{~cm}$ & $\begin{array}{l}\text { Torsional spring, } \\
\text { cam. }\end{array}$ & $\begin{array}{c}\text { Lightweight material, click } \\
\text { mechanism, adjustable take-off angle, } \\
\text { high endurance }\end{array}$ & $\begin{array}{l}\text { Lack of self-righting } \\
\text { mechanism and } \\
\text { landing control }\end{array}$ & \\
\hline
\end{tabular}

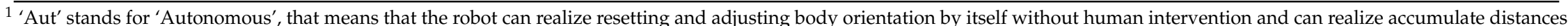
after jumping several times. "Y" represents 'Yes'; "N" represents 'No'. 


\subsection{Take-off Velocity}

Compared to the take-off angle, it is much easier for animals to control the take-off velocity, by properly managing the energy stored in elastic components such as muscles. Take-off velocity of locusts is determined by the amount of energy stored in elastic extensor and semilunar process of hind legs before jumping $[52,216,217]$. It is much harder for miniature jumping robots, as most miniature intermittent jumping robots are endowed with elastic components presenting fixed initial and final points. The energy stored inside the elastic components is constant, and most of the existing jumping robots cannot control the take-off velocity. One special case is the jumping robot proposed by Jung et al. [148], which has two end points for energy storage in its elastic components; it can achieve two different take-off velocities.

It is easier for miniature jumping robots with explosive energy to adjust the take-off velocity compared to the jumping robots with elastic components. For example, a spherical jumping robot based on combustion of flammable gas, which is proposed by Loepfe et al. [36], can change the take-off velocity by properly managing the gas ratio and flow rate of flammable gas.

The soft robot developed by $\mathrm{Hu}$ et al. [37] and characterized by multi-locomotion mode can theoretically change the take-off velocity and direction by changing the external magnetic field intensity and direction.

The ball crawling and jumping robot based on SMA proposed by Sugiyama et al. $[29,30]$ can control the deformation and initial shape of SMA to change the stored energy and energy conversion rate and, thus, change the take-off velocity.

\subsection{Take-off Stability}

For most animals, jumping stability is the key for a successful landing. With the exception of click-beetles, that use the rolling velocity after take-off phase to realize body resetting [218], most jumping animals adopt different strategies to keep a stable body pitch angle after take-off. The most adopted strategy in animals is to ensure the contact force passing through the centroid during the whole take-off phase. Locusts can adjust the centroid close to the thrust vector before jump occurs, exploiting the contraction of the dorso-longitudinal muscles during the jump to counterbalance the torque produced by the trust itself. In kangaroos' jumping, instead, the movement of the tail is the key to ensure the take-off stability [41].

Only a small number of existing jumping robots can achieve stable jumping. One strategy is to use a balanced tail [41], and another strategy is to ensure that the contact force passes through the centroid during the take-off phase. Zero-momentum is considered into the mechanism design of "Salto" [159], a one-DOF locust-inspired jumping robot [113]. Take-off stability is very important in jumping robots because it decides the rotation velocity after take-off and the effort required for aerial righting in flight phase.

\section{Aerial Righting}

\subsection{Aerial Righting in Jumping Animals}

The aerial righting strategies adopted by animals can be subdivided into: (i) aerial righting by way of aerodynamic torque; (ii) aerial righting by way of inertia; (iii) using dragline silk.

\subsubsection{Aerial Righting by Way of Aerodynamic Torque}

Aerial righting in animals with wings: Animals capable of flapping flight show excellent ability in aerial righting through asymmetric motion, both in excursion and velocity, between their left and right wing. This strategy is adopted by a lot of birds [219-221] and insects [222-226]. The tail movement in birds and the abdomen movement in insects help maneuver their flight [227-230]. In addition to flapping, a lot of animals developed gliding flight using wings [231,232], patagial membranes [233-235], or the extended body skeletons [236,237]. During gliding, the ability to 
substantially alter the aerodynamic force in order to reorient the body is the key for the transition between leaping and gliding and allows those arboreal animals to travel long distances between perches with lower risk of damage [235]. Nonequilibrium glides are demonstrated in a lot of gliding animals and are used to maneuver their gliding trajectories and landing postures [238-242].

Aerial righting in wingless animals: The active controllability over the aerodynamic forces using legs or body parts are demonstrated in some wingless insects. In the descending phase of ants, high speed videos show that they can maneuver targeted landing by using bilaterally asymmetric motions of the hind legs to affect body rotations around the vertical axis $[243,244]$. After being released upside-down, wingless nymphal stick insects can actively modulate limb position. The associated aerodynamic torques is used for dorsoventral reorientation and body posture stabilization [245].

\subsubsection{Aerial Righting by Way of Inertia}

A lot of animals can realize aerial righting through inertia by using the movement of their torsos, tails or abdomens, and dragline silk.

Torso-induced righting: Why do cats have nine lives? This is mainly correlated to cats' righting reflex, consisting of a cats' innate ability to orient itself as it falls in order to land on its soft feet pads. This is the reason why they have an unusually flexible backbone and no functional collarbone [246]. A lot of researchers conducted experiments, developed mathematical models, and even realize some prototypes to demonstrate this mechanism [247-250]. Similar strategies are found also in mice [251,252] and rabbits [253]. Mantis also uses exchanges of angular momentum between three rotating body parts in order to achieve targeted jumping and stable landing [254].

Tail/abdomen-induced aerial righting: The tail is widely used in animals to balance and maneuver during locomotion. It is reported that geckos are able to right themselves by swinging their tails after falling down, in order to maneuver the yaw movement of their bodies with circular tail motions [255]. The importance of tail in lizards' locomotion is also well demonstrated both during jumping and arboreal maneuver [256-259]. Even the jumping performances, including jump distance and take-off velocity, are not affected by the surgical tail removal, while the aerial righting ability is strongly compromised after tail removal [258]. Most existing mammals are entitled with a long tail, while their function varies [260,261]. Bipedal hopping is one kind of terrestrial locomotion adopted by a few mammals (kangaroos, wallabies, and kangaroo rats et al.). All these mammals have remarkably similar limb morphology; in addition, they have very long tails, used to maintain stability [163,165,262,263]. The importance of tail is also mentioned in high speed locomotion of cheetahs, that includes rapid acceleration, rapid break, rapid turning, and balancing [264-269]. In addition to the use of body twisting for balancing [247-250], cats also use the tail to balance themselves and maintain stability under perturbations [270].

In invertebrate animals without tail, aerial righting is achieved via the swing of their abdomens. In moths, the articulation of the thoracic-abdominal joint is used to redirect an average lift force provided by the wings [271]. This articulation is sufficient to maintain stable hovering within a slim margin. Both abdomen swing and forewing rotation have positive effects on locusts' body pitch angle control [111].

\subsubsection{Using Dragline Silk}

In addition to the before-mentioned two aerial righting strategies, salticids also have a different mechanism for aerial stability, exploiting dragline silk [66]. Salticids can use the silk force to reverse the body pitch in order to achieve a desirable and optimal landing posture. Without silk, they slip or even tumble, spending a long time in landing.

\subsection{Aerial Righting in Jumping Robots}

Most existing miniature jumping robots are not able to perform aerial righting, contrary to what is commonly found in animals [272]. For what concerns the majority of intermittent jumping robots, researchers focused mainly on the resetting mechanism design, ignoring aerial stability. Aerial righting 
ability is a good premise to achieve a precise landing in continuous jumping robots $[160,161]$. The most adopted aerial righting strategies include one/two-DOF balancing tail, gliding wings, and propellers.

\subsubsection{One/Two-DOF Balanced Tail}

The main strategy adopted for a great balance consists of adding a dedicated tail. Researchers found a positive balancing effect of tail in lizards'/geckos' locomotion [256] and applied this strategy to a terrestrial robot. This tailed robot can right itself rapidly in a fall and smoothly transit between surfaces of different slopes, though active tail adjustment, used to achieve zero net angular momentum maneuvering [257]. Zhao et al. [215] designed a balancing tail for their jumping robots to achieve aerial righting and compared the dynamic performance of different controllers. Liu et al. [169] adopted open-loop control strategies for the balanced tail of their kangaroo-inspired jumping robot, and the aerial righting effect was significant during the first jumps. As errors caused by the landing impact are accumulated during functioning, this jumping robot cannot realize the balance of its body with an open-loop control strategy. Due to the short duration of the jump and the intense landing impact, the use of a balanced tail to achieve the aerial righting requires precise design of the controller and high motor response frequency. This balance strategy is widely adopted by robots [41,269-273]. In addition, researchers designed a 2-DOF tail to achieve better balance performances of robots [268,274-276].

\subsubsection{Gliding Wings}

Another strategy for aerial righting currently adopted in robots is represented by gliding wings, which can help the robot increase aerial stability by increasing air resistance. For example, Kovac et al. [92] added gliding wings to their locust-inspired jumping robot, and similar jumping and gliding robots were developed by Woodward et al. [150-153] and Beck et al. [98]. Woodward, in particular, proposed a jumping and gliding robot called "MultiMo-Bat" [150-154] that exploits the principle of components sharing (nearly $70 \%$ of robot mass is involved in two locomotion modes, preserving $80 \%$ jumping performance).

Recently Truong et al. [277] designed a bioinspired flapping-wing-assisted jumping robot. The flapping mode helps increase the jumping height by $10 \%$. The possibility of using flapping wings to realize aerial stability after take-off is demonstrated.

\subsubsection{Propellers}

The recently developed galago-inspired jumping robot "Salto- $1 \mathrm{P}$ " can realize aerial righting by means of a coordinated action of the balanced tail and two added propellers. It can achieve precise controlled jumping in three-dimensional space $[160,161]$. This strategy is rare to see in animals' kingdom.

By comparing the animal's agile aerial righting and shortcomings of current jumping robots, researchers can get inspiration from animals and develop more concise designs and control solutions in robots' aerial righting.

\section{Landing Buffering and Resetting Mechanisms in Animals and Robots}

The main purpose of jumping in animals is escaping from dangers. It is quite normal to see some animals loose stability after take-off and land on their back, especially in animals that adopt intermittent jumping strategy, while kangaroos or galagoes are able to land softly and jump again thanks to their compliant body structure and flexible leg movements. These animals can absorb shock without damaging themselves during landing and be ready for the next jump or other locomotion modes.

After take-off, locusts adopt flapping or gliding to move longer and maneuver their body posture to be ready for landing. During landing, the locomotion of their legs can absorb most part of landing shock [110]. In some animals, the peak contact force during landing is three times higher than the peak force during take-off $[278,279]$. The elastic tendons in legs can deform to absorb the landing shock, and the energy stored in deformed tendons can be reused for the next jump. The tendons work as power amplifiers and achieve metabolic energy conservation [280]. 
Animals which execute continuous jumping do not need to reset themselves after landing, while intermittent jumping animals landing on their back have to reset themselves in order to prepare for next jump. When humans fall down, they reset themselves very easily with the support of hands. Similar strategies are also found in insects: when they fall down on one side of their body, they can use the coordination of their legs to reset themselves [107]. Similar mechanisms are used by turtles: they coordinate the movement of their head and legs to reset themselves when they are turned upside down [281].

The ability to reset after falling and the ability to land softly are the most important abilities in intermittent jumping robots and continuous jumping robots. In existing jumping robots, the adopted strategies can be classified into four types: (i) Active resetting using support legs; (ii) Passive resetting assisted by flexible frame; (iii) Gliding wings that help land softly; (iv) Elastic buffering legs that help absorb impact.

\subsection{Active Resetting Using Support Legs}

Aerial righting and land buffering are ignored in most of the existing miniature intermittent jumping robots. After falling down, most jumping robots frequently land on their backs or land on their sideways. A motor is used to actuate a support leg to rotate around a fixed point, and the robot can reset passively under gravity after the robots reach a certain position. For example, the wheeled jumping robot proposed by Chen et al. [282] rotates the support legs, that are linked to the jumping legs through a joint, to reset itself. The first generation of locust jumping robots proposed by Zhang et al. [101] uses a support tail to reset after landing. Zhao et al. [214] added two symmetrical support legs on both sides of the fuselage to achieve robot resetting. The second generation of jumping robots proposed by Burdick et al. [12] firstly puts the six-bar jumping mechanism in contact after landing, and then uses the plane support legs to reset the body, preparing for the next jump.

\subsection{Passive Resetting Assisted by Flexible Frame}

Most of the existing miniature jumping robots use an auxiliary frame to achieve land buffering and passive resetting, using a low gravity center similar to the tumbler [36,283]. For example, the carbon fiber frame in the locust-inspired jumping robots [89] absorbs most of the landing impact and protects the internal jumping mechanism. At the same time, since the center of gravity becomes lower when the jumping mechanism contracts, the robot can realize passive resetting. The "Jollbot" ball rolling and jumping robot developed by Armour et al. [10], and the single motor driven wheeled rolling and jumping robot developed by Ho et al., [284], both adopt similar structures to absorb landing shock and resetting passively. In addition, the added frame structure also introduces new locomotion modes to jumping robots. Some examples are "Jollbot", a wheeled jumping robot developed by Ho et al. [284], able to perform rolling using SMA as actuator and deformation principle, and the jumping robot developed by Sugiyama et al. [29-31], able to roll using the ball shape frame. Meantime, the frame structure increases the body size and mass of jumping robots significantly, so the jumping performances and possible applications of designed jumping robots are limited.

\subsection{Gliding Wings Help Landing}

"Glumper", the jumping and gliding robot proposed by the University of Bath [10], represents the first combination of jumping and gliding. Due to the increased air resistance, added body weight, and friction caused by foldable mechanism, jumping height and distance are severely decreased [285]. Inspired by the wing structure of insects, Kovac et al. [92,286-288] designed three different wing foldable mechanisms inspired by bats, butterflies, and locusts, based on their previous gliding robots. They compared the jumping performances and flight trajectories of robots: without wings, with fixed wings, and locust-inspired foldable wings. They made robots jump from a $2 \mathrm{~m}$ high platform. Results demonstrated that, by adding fixed wings, it is in most cases possible to increase flight distance and decrease $54 \%$ the landing impact [92]. Jumping height, instead, decreased from $1.4 \mathrm{~m}$ to $12 \mathrm{~cm}$ because of the increased body mass. 
Experimental results confirmed that the combination of gliding and jumping can greatly increase the flight distance and reduce landing shock. Desbiens et al. proposed a jumping and gliding robot, studied the effect of gliding wings on extending the flight distance [289], and found that the foldable wings have a significant effect on reducing the resistance during the ascending phase.

Beck et al. [98] added foldable gliding wings and tails to their developed locust-inspired jumping robot, in order to help it achieve aerial righting and reduce landing shock. Experimental results show that the foldable wing, compared to the fixed wing, works better both in increasing the jumping height and in extending flight distance by decreasing gliding angle. After adding the foldable wing, their jumping robot can jump $1.7 \mathrm{~m}$, which gives enough flight time for the foldable wing to unfold at the peak point of trajectory. Gliding/flapping is a common locomotion mode adopted by animals, and their actuation mechanisms is more flexible, simple, and light. In contrast, the wing flapping and unfolding wing mechanisms used in robots are much more complex both in mechanical design and control.

\subsection{Elastic Buffering Legs to Absorb Impact}

Chen et al. studied the land buffering mechanism of locusts and performed kinematic analysis to study the relationship between legs postures and landing positions $[110,290]$. The new proposed multibranch elastic legs can reduce the maximum contact force, increase the absorbed energy per distance, and achieve better land buffering. These basic theoretical studies laid the foundation for the development of bionic jumping robots. In continuous jumping robots, like "BionicKangaroo" [41], "KenKen" [177,178], and "Salto" [157,158], the elastic springs placed in their legs works similar to tendons in real animals' landing: they can absorb part of the landing shock and store energy.

\section{Discussion}

In order to fulfil important requirements such as agility, adaptability, and maneuverability of robotic artefacts, researchers often take inspiration from real animals, trying to imitate their structures and actions. However, there still are a lot of issues to be addressed in jumping robotic artefacts. In this section, they will be illustrated, together with some interesting prospects for jumping robots.

\subsection{Issues to Still Be Addressed}

\subsubsection{Modeling}

The goal of designing a jumping robotic artefact is to make it explore uneven terrains with the possibility to overcome obstacles. This means the artefact must be robust and self-adaptive. SLIP-based jumping robots are successfully developed, while open-chain structures and close-loop control are still rarely adopted due to their complexity. The modeling of these structures is strategic because it would finally contribute to the realization of really autonomous robots.

\subsubsection{Materials}

Different jumping performances imply different requirements that in turn lead to different properties of materials. In many cases these properties contrast with each other, being not compatible. For example, a mini robot requires light materials to jump higher and further, but this way it risks being too fragile to withstand the shock of landing. Actuators are another representative case: their ideal characteristics are small volume, high energy density, and light mass. These are all fulfilled by SMA materials, already applied in [30,32] but with annoying drawbacks: the excessive energy dissipation in the deformation process and the impossibility to realize energy on-board due to the high actuating voltage required. For these reasons, the application of new materials is desirable. 


\subsubsection{Mechanical Structure}

Kinematics of jumping robots can be very complex, mainly when multiple locomotion modes are involved. Thus, the effective and efficient application of mechanical components is a key issue to limit volume and mass of artefacts. An effective method is the components sharing adopted in [151,152], which realizes gliding and jumping with light mass, but still few researchers are working on this issue. Authors think that components sharing should be largely adopted when designing jumping robots characterized by multi-locomotion mode.

Another important issue is vibration prevention, through the cooperation of qualitative control methods and light materials. Recently, soft materials have been placed in the bottom of robots achieving soft landing and reducing vibrations. Researchers are encouraged to find out new schemes to solve the problem of vibrations.

\subsubsection{Actuation Mechanisms}

Shocking and mechanical vibrations are often due to actuators, especially in miniature robots in which the smoothness of trajectory is hardly penalized. New technologies for fabricating highly compliant mechanical actuators are urgent, since actual micromotors entail complex manufacturing processes and high production costs.

\subsubsection{Miniaturization}

Miniaturization contributes to obtain higher jumping performances and to reduce vibrations. However, to achieve better locomotion performances, jumping artefacts must also be endowed with other locomotion modes such as running, walking, rolling, and gliding. Obviously, in miniature robots, multilocomotion is in contrast with the limited design space. Engineers should seek for satisfactory tradeoffs, perhaps through the components sharing method.

\subsubsection{Control Algorithms}

Open-loop control and simple feedback control are still primary methods in jumping robots, although they cannot guarantee trajectory optimization with characteristics of smoothness, accuracy, self-righting, and stability. The main reason hampering a wide diffusion of advanced controls is that closed-loop controls would require additional sensors, controllers, and actuators, which would add significant weight, drastically reducing jumping performances of robots. Moreover, close-loop controls are often model-based, so, without an accurate mathematical model they would be totally useless. Finally, they require high computational resources, that are not installable on a robotic platform, especially in the case on miniature jumping robots. Thus, studies still have to address the contradiction between high performance and low computational complexity.

\subsubsection{High Energy Density}

High energy density is important to achieve higher jumping height and distance. In order to increase energy density, researchers begun to employ the method of multiple storage elements, that provide power at the same time. In addition, new materials and mechanisms for innovative energy storage techniques are still an open issue.

\subsubsection{Trajectory Optimization}

Trajectory planning is related to several aspects such as distance, angle, height, and safety. Scientists seldom have realized the overall closed loop for the jumping process, including judging feasibility, computing take-off angle and required energy, and executing jumping action. The added sensors and the excessive computational resource make it impossible to develop miniature jumping robots with real-time trajectory planning and optimization. The research on these aspects needs to be 
increased, mainly focusing on the enhancement of continuous jumping ability and precisely controlled landing, that are fundamental requirements for an accurate path planning.

\subsection{Prospects of Jumping Robots}

Until know, there are few jumping robotic artefacts that have been tested in outdoor unknown complex environment. Considering the actual status of research and the limitations highlighted in Section 6.1, we are going to discuss some prospective developmental trends on the design of bioinspired jumping robots.

One key issue still unsolved issue is the realization of miniature jumping robots with a highly efficient powering system and without mechanical vibrations. Micro electromechanical systems (MEMS), already applied in general instrumentation such as semiconductors and integrated circuits, may be also used to optimize the ratio between performances and weight of the mechanical structure of miniature robots. Despite their expensive cost, the integration of MEMS sensors and actuators in a very limited space would decisively bring the efficiency of jumping robots to the next level, opening new scenarios of applicability.

On the side of power consumption, instead, two ways of energy optimization have been tried till now: reducing energy dissipation and increasing stored energy. Usually, these two methods are alternative to each other. For example, "JumpRoACH" [148] combines a linear spring with a torsional spring to increase the amount of stored energy, while MultiMo-Bat $[150,151,153]$ is focused on the optimization of energy efficiency through a proper control. It would be desirable to use both methods, perhaps by exploiting precision components to increase energy efficiency without taking too much space, that would remain available for energy storage components.

Artificial intelligence technologies have been massively adopted in mobile robots since 2000s, to perceive the surrounding environment and realize autonomous motion, path planning, and navigation [291-295]. The emerging intelligence methods [296,297], such as meta learning, deep learning, and brain-inspired intelligence, supported with high precision navigation and localization systems, could help in trajectory optimization of bioinspired jumping robots, with the possibility of a further enhancement by means of. Artificial intelligence may help jumping artefacts learn and analyze new contexts autonomously, interacting with other agents. This would mean better robustness and adaptability of robots in unstructured scenarios.

Multi-locomotion mode is often used in jumping robots to increase mobile ability, but with the drawback of an increased energy consumption. One possibility is to increase the amount of stored energy, but it would entail bigger masses and weigh. A more convenient option is to decrease energy consumption by exploiting the compliant of soft materials. They are already the object of popular research and have been applied in several jumping robots to reduce vibrations and shock from collisions. The exploitation of soft materials for the manufacturing of actuators and energy storage systems would help augment energy efficiency of jumping robots.

In addition to those complicated scenarios of application mentioned in the introduction (batter field reconnaissance, archaeological exploration, antiterrorism operations, interstellar detection), some activities in simplified indoor scenarios can also be performed by jumping robots, such as sensor networks, home service, accompany, and entertainment.

\section{Conclusions}

In this last section, some interesting future trends for jumping robots will be discussed referring to the characteristics of their biological counterparts in animal kingdom.

Thanks to the application of new technologies and new materials $[37,120]$, the size of jumping robots is becoming more and more similar to the corresponding animals' size, and the jumping performances already exceed animals in distance and height, while there is still an evident gap between the controls capabilities of animals and those of robots, particularly in the case of miniature jumping robots, as summarized in Table 3. Researchers focusing on micromechanics should work together, 
seeking for an even more exhaustive comprehension of animals' locomotion strategies, in order to significantly improve the performance of their robotic artifacts.

Table 3. Controllability and strategies during jumping used in animals and robots.

\begin{tabular}{|c|c|c|}
\hline Aspects & Strategies Used in Animals & Strategies Used in Robots \\
\hline Take-off angle & Orientation of hindlegs. & $\begin{array}{l}\text { (1) Changing some components (bar length, } \\
\text { gear ratio) manually; } \\
\text { (2) Adjusting the position of the counterpart; } \\
\text { (3) Adjusting the body pitch angle using } \\
\text { support bar. }\end{array}$ \\
\hline Take-off direction & $\begin{array}{l}\text { (1) Orientation of two fore legs; } \\
\text { (2) Orientation of two hind legs. }\end{array}$ & $\begin{array}{l}\text { (1) Rotating the whole robot around axis; } \\
\text { (2) Discontinuous rotation the body around } \\
\text { fixed tail; } \\
\text { (3) Differential wheels. }\end{array}$ \\
\hline Take-off velocity & $\begin{array}{l}\text { Stored energy inside muscle and } \\
\text { elastic components. }\end{array}$ & $\begin{array}{l}\text { (1) More than one end points of energy } \\
\text { storage component; } \\
\text { (2) Changing the gas ratio and flow rate of } \\
\text { flammable gas; } \\
\text { (3) The deformation and initial shape of SMA; } \\
\text { (4) External magnetic field and direction. }\end{array}$ \\
\hline Take-off stability & $\begin{array}{l}\text { (1) Ensuring that contact force } \\
\text { passes through the centroid and } \\
\text { counter of the stomach's } \\
\text { contraction; } \\
\text { (2) Balancing tail. }\end{array}$ & $\begin{array}{l}\text { (1) Balancing tail; } \\
\text { (2) Zero-momentum by ensuring that contact } \\
\text { force passes through the centroid during } \\
\text { take-off phase. }\end{array}$ \\
\hline Aerial righting & $\begin{array}{l}\text { (1) Aerial righting by way of } \\
\text { aerodynamic torque; } \\
\text { (2) Aerial righting by way of } \\
\text { inertia; } \\
\text { (3) Using dragline silk. }\end{array}$ & $\begin{array}{l}\text { (1) One/two-DOF balanced tail; } \\
\text { (2) Gliding wings; } \\
\text { (3) Propellers. }\end{array}$ \\
\hline $\begin{array}{l}\text { Landing buffer and } \\
\text { resetting mechanism }\end{array}$ & $\begin{array}{l}\text { (1) Compliant body structure } \\
\text { helps absorb shock; } \\
\text { (2) Landing softly with help of } \\
\text { tendons in legs; } \\
\text { (3) Resetting with help of legs. }\end{array}$ & $\begin{array}{l}\text { (1) Active resetting using support legs; } \\
\text { (2) Passive resetting assisted by flexible frame; } \\
\text { (3) Gliding wings help landing; } \\
\text { (4) Elastic buffering legs help absorb impact. }\end{array}$ \\
\hline
\end{tabular}

In the following, authors focus on some key aspects, present in the animal kingdom but still missing in jumping robots. The strategies that jumping animals adopt to control the take-off angle, direction, velocity, and realize aerial righting, could inspire engineers to develop their robotic artefacts. The most adopted strategy to realize land buffering and passive resetting in jumping robots consists of exploiting an added flexible frame that surrounds the robot's body. This strategy is rarely found in animals. The flexible frame helps realize re-jumping, but it also increases body weight and penalizes the performance. This refers to the differentiation between continuous jumping and intermittent jumping. Animals like kangaroos adopt continuous jumping and are able to realize landing buffing. This way, they restore part of the energy from landing and reuse it for the next jump. Instead, animals like locusts adopt intermittent jumping and, after landing, they need to reset the orientation of their body to prepare for next jump. The situation is the same in jumping robots. So, depending on whether continuous or intermittent jumping is adopted, researchers need to develop different strategies. This problem is not solved until now. There are few jumping robots that can realize re-jumping but the added mechanisms they exploit could increase the body weight, which sacrifices the jumping performances. Key feature like rigid-flexible body, buffering legs/gliding wings, and flapping wings are adopted in animals to solve landing problems without increasing body weight. Based on this thorough study of the status 
of research about the jumping animals and bioinspired jumping robots, the developmental trends of bioinspired jumping robots are predicted and listed as follows.

Jumping in combination with other locomotion modes: Jumping is characterized by short-time high power output and, thus, is an energy-consuming activity. For this reason, most animals with outstanding jumping abilities always adopt other locomotion modes. Kangaroos can use their two front legs for walking; the common locomotion mode adopted by tigers and cheetahs is walking. Fast speed running and jumping are used mostly during hunting. In addition, frogs can walk and swim with their big feet and use jumping mainly for surviving reasons, both on land and in water. Insects like fleas, locusts, and froghoppers can walk with six legs and jump with their strong hind legs. Locusts can rely on flapping and gliding to achieve long-distance migration and they use jumping to initiate flapping. During landing of jumping robots, a big impact force is generated, with the risk of damaging some mechanical components. Moreover, the single jumping locomotion mode reduces the reliability and life cycle of jumping robots. Combining jumping with other locomotion modes, such as flapping, gliding, crawling, wheeling, and rolling, will increase the agility and robustness of jumping robots.

Swarm jumping robots: Miniature jumping robots have simple structure, superior jumping performance, and low cost. With the rapid development of battery technology, communication technology and micro-scale manufacturing technology, low-cost miniature jumping robots will likely work collaboratively in dangerous tasks, such as interstellar exploration, archaeological exploration, military reconnaissance, and rescue search. In ref. [105,106], swarm jumping robots are used to monitor environments.

Application of elastic actuators and new materials/compliant structures: There are more and more applications of elastic actuators in jumping robots. "Salto" $[157,158]$ can achieve outstanding jumping performances, using similar landing buffering and energy restoring strategy as animals. It prepares for the next jump using series elastic actuators that store and release energy.

The animal's body structure is a combination of rigid material and soft material. Vertebrate animals' rigid bones are covered by soft muscles and connected through flexible joints. The soft body of locusts can absorb partially the landing shock. This has inspired designers to adopt a combination of rigid and soft structural elements to provide their products the capability to effectively absorb the shock of landing without compromising mechanical strength. For this purpose, the main trend is to employ composite and smart materials because they are lightweight, they adapt to different environmental scenarios and, overall, they can store an high density of energy. New developments in materials also provide new solutions to solve driving, to improve performances, and to perform land buffering in jumping robots. The addition of a carbon fiber frame to the $7 \mathrm{~g}$ locust-inspired jumping robot developed by Kovac et al. solved the problem of land buffering effectively [90]. The application of SMA in jumping robots exploits the phase transition of material to combine crawling and rolling with jumping [31]. The multi-locomotion mode soft robot developed by Hu et al. [37] consists of tiny magnet particles distributed evenly inside soft rubber. It can achieve a variety of locomotion modes by changing the external magnetic field.

Environment perception: Animals can perceive the ground information through their visual and tactile systems. They can plan their own trajectories according to the size and position of the obstacles. Similar environmental sensations and trajectories plan based on environment information are important issues that jumping robots still must solve before they can leave laboratories to be applied in real unstructured environments. For instance, substrates of different properties, like compliance and roughness levels, may hardly impact the jumping performances of animals and robots. While jumping animals have developed adaptative strategies to counteract eventual disadvantageous conditions of ground [80,81], most existing jumping robots lack in perception and adaptability.

To sum up, in this paper authors systematically reviewed the research status of bioinspired jumping robots and the jumping mechanism of their biological models. They compared the strategies adopted to solve issues such as the controllability of jump (take-off angle, take-off direction, take-off velocity, 
and take-off stability), aerial righting, land buffering and resetting, and predicted the developmental trends of bioinspired jumping robots. The application of compliant structures, elastic actuators, and new materials help decrease the body weight and improve the jumping performance. Miniature jumping robots will be highly similar to animals both in shape and functioning. They will be likely endowed with multi-locomotion modes, work in groups, and complete tasks collaboratively with environmental sensation abilities.

Author Contributions: Conceptualization, X.M. and D.R.; resources, W.G. and C.S.; writing—original draft preparation, X.M., D.R. and D.Z.; writing—review and editing, W.G., D.R., M.M., F.I. and C.S.; visualization, X.M., M.M. and D.Z.; supervision, W.G., D.R. and C.S.; project administration, W.G., D.R. and C.S. All authors have read and agreed to the published version of the manuscript.

Funding: This research was funded by National Key Research and Development Program of China, grant number 2017YFB1300101.

Conflicts of Interest: The authors declare no conflict of interest. The funders had no role in the design of the study; in the collection, analyses, or interpretation of data; in the writing of the manuscript, or in the decision to publish the results.

\section{References}

1. Gordon, M.S.; Blickhan, R.; Dabiri, J.O.; Videler, J.J. Animal Locomotion: Physical Principles and Adaptations; CRC Press; Taylor \& Francis Group: Boca Raton, FL, USA, 2017. [CrossRef]

2. Alexander, R.M. Principles of Animal Locomotion; Princeton University Press: Princeton, NJ, USA, 2002. [CrossRef]

3. Biewener, A.; Patek, S. Animal Locomotion; Oxford University Press: Oxford, UK, 2018.

4. Romano, D.; Donati, E.; Benelli, G.; Stefanini, C. A review on animal-robot interaction: From bio-hybrid organisms to mixed societies. Biol. Cybern. 2018, 113, 1-25. [CrossRef]

5. Taylor, G.; Triantafyllou, M.S.; Tropea, C. Animal Locomotion; Springer: Des Moines, IA, USA, 2010. [CrossRef]

6. Mammal's Locomotion. Available online: http://mammals-locomotion.com (accessed on 20 August 2020).

7. Sayyad, A.; Seth, B.; Seshu, P. Single-legged hopping robotics research-A review. Robotica 2007, 25, 587-613. [CrossRef]

8. Kram, R.; Dawson, T.J. Energetics and biomechanics of locomotion by red kangaroos (Macropus rufus). Comp. Biochem. Physiol. Part B Biochem. Mol. Biol. 1998, 120, 41-49. [CrossRef]

9. Scott, J. The locust jump: An integrated laboratory investigation. Adv. Physiol. Educ. 2005, 29, 21-26. [CrossRef]

10. Armour, R.; Paskins, K.; Bowyer, A.; Vincent, J.; Megill, W. Jumping robots: A biomimetic solution to locomotion across rough terrain. Bioinspir. Biomim. 2007, 2, S65. [CrossRef]

11. Wei, D.; Ge, W. Research on one bio-inspired jumping locomotion robot for search and rescue. Int. J. Adv. Robot. Syst. 2014, 11, 168. [CrossRef]

12. Burdick, J.; Fiorini, P. Minimalist jumping robots for celestial exploration. Int. J. Robot. Res. 2003, 22, 653-674. [CrossRef]

13. Kaplan, M.H.; Seifert, H.S. Hopping transporters for lunar exploration. J. Spacecr. Rocket. 1969, 6, 917-922. [CrossRef]

14. Raibert, M.H. Legged Robots That Balance; MIT Press: Cambridge, MA, USA, 1986. [CrossRef]

15. Berkemeier, M.D.; Fearing, R.S. Sliding and hopping gaits for the underactuated acrobot. IEEE Trans. Robot. Autom. 1998, 14, 629-634. [CrossRef]

16. Rad, H.; Gregorio, P.; Buehler, M. Design, modeling and control of a hopping robot. In Proceedings of the 1993 IEEE/RSJ International Conference on Intelligent Robots and Systems, Yokohama, Japan, 26-30 July 1993; Volume 3, pp. 1778-1785. [CrossRef]

17. M'Closkey, R.T.; Burdick, J.W. Periodic motions of a hopping robot with vertical and forward motion. Int. J. Robot. Res. 1993, 12, 197-218. [CrossRef]

18. Hyon, S.H.; Emura, T. Quasi-periodic gaits of passive one-legged hopper. In Proceedings of the IEEE/RSJ International Conference on Intelligent Robots and Systems, Lausanne, Switzerland, 30 September-4 October 2002; Volume 3, pp. 2625-2630. [CrossRef] 
19. François, C.; Samson, C. A new approach to the control of the planar one-legged hopper. Int. J. Robot. Res. 1998, 17, 1150-1166. [CrossRef]

20. Brown, B.; Zeglin, G. The bow leg hopping robot. In Proceedings of the 1998 IEEE International Conference on Robotics and Automation (Cat. No. 98CH36146), Leuven, Belgium, 20 May 1998; Volume 1, pp. 781-786. [CrossRef]

21. Pratt, G.A. Legged robots at MIT: What's new since Raibert? IEEE Robot. Autom. Mag. 2000, 7, 15-19. [CrossRef]

22. Mochiyama, H.; Watari, M.; Fujimoto, H. A robotic catapult based on the closed elastica and its application to robotic tasks. In Proceedings of the 2007 IEEE/RSJ International Conference on Intelligent Robots and Systems, San Diego, CA, USA, 29 October-2 November 2007; pp. 1508-1513. [CrossRef]

23. Yamada, A.; Watari, M.; Mochiyama, H.; Fujimoto, H. An asymmetric robotic catapult based on the closed elastica for jumping robot. In Proceedings of the 2008 IEEE International Conference on Robotics and Automation, Pasadena, CA, USA, 19-23 May 2008; pp. 232-237. [CrossRef]

24. Yamada, A.; Mameda, H.; Mochiyama, H.; Fujimoto, H. A compact jumping robot utilizing snap-through buckling with bend and twist. In Proceedings of the 2010 IEEE/RSJ International Conference on Intelligent Robots and Systems, Taipei, Taiwan, 18-22 October 2010; pp. 389-394. [CrossRef]

25. Yamada, A.; Watari, M.; Mochiyama,H.; Fujimoto,H. A robotic catapult based on the closed elastica with a high stiffness endpoint and its application to swimming tasks. In Proceedings of the 2008 IEEE/RSJ International Conference on Intelligent Robots and Systems, Nice, France, 22-26 September 2008; pp. 1477-1482. [CrossRef]

26. Tsuda, T.; Mochiyama, H.; Fujimoto, H. Quick stair-climbing using snap-through buckling of closed elastica. In Proceedings of the 2012 International Symposium on Micro-NanoMechatronics and Human Science, Nagoya, Japan, 4-7 November 2012; pp. 368-373. [CrossRef]

27. Scarfogliero, U.; Stefanini, C.; Dario, P. The use of compliant joints and elastic energy storage in bio-inspired legged robots. Mech. Mach. Theory 2009, 44, 580-590. [CrossRef]

28. Wei, D.; Gao, T.; Li, Z.; Mo, X.; Zheng, S.; Zhou, C. Hybrid Inspired Research on the Flying-Jumping Locomotion of Locusts Using Robot Counterpart. Front. Neurorobot. 2019, 13, 87. [CrossRef]

29. Sugiyama, Y.; Hirai, S. Crawling and jumping by a deformable robot. Int. J. Robot. Res. 2006, 25, 603-620. [CrossRef]

30. Matsuyama, Y.; Hirai, S. Analysis of circular robot jumping by body deformation. In Proceedings of the 2007 IEEE International Conference on Robotics and Automation, Roma, Italy, 10-14 April 2007; pp. $1968-1973$. [CrossRef]

31. Sugiyama, Y.; Shiotsu, A.; Yamanaka, M.; Hirai, S. Circular/spherical robots for crawling and jumping. In Proceedings of the 2005 IEEE International Conference on Robotics and Automation, Barcelona, Spain, 18-22 April 2005; pp. 3595-3600. [CrossRef]

32. Bartlett, N.W.; Tolley, M.T.; Overvelde, J.T.; Weaver, J.C.; Mosadegh, B.; Bertoldi, K.; Whitesides, G.M.; Wood, R.J. A 3D-printed, functionally graded soft robot powered by combustion. Science 2015, 349, 161-165. [CrossRef]

33. Wang, H.; Luan, Y.; Oetomo, D.; Wang, Z. Design, analysis and experimental evaluation of a gas-fuel-powered actuator for robotic hoppers. IEEE ASME Trans. Mechatron. 2015, 20, 2264-2275. [CrossRef]

34. Miao, Z.; Mo, J.; Li, G.; Ning, Y.; Li, B. Wheeled hopping robot with combustion-powered actuator. Int. J. Adv. Robot. Syst. 2018, 15, 1729881417745608. [CrossRef]

35. Shepherd, R.F.; Stokes, A.A.; Freake, J.; Barber, J.; Snyder, P.W.; Mazzeo, A.D.; Cademartiri, L.; Morin, S.A.; Whitesides, G.M. Using explosions to power a soft robot. Angew. Chem. Int. Edit. 2013, 125, $2964-2968$. [CrossRef]

36. Loepfe, M.; Schumacher, C.M.; Lustenberger, U.B.; Stark, W.J. An untethered, jumping roly-poly soft robot driven by combustion. Soft Robot. 2015, 2, 33-41. [CrossRef]

37. Hu, W.; Lum, G.Z.; Mastrangeli, M.; Sitti, M. Small-scale soft-bodied robot with multimodal locomotion. Nature 2018, 554, 81. [CrossRef]

38. Li, F.; Liu, W.; Fu, X.; Bonsignori, G.; Scarfogliero, U.; Stefanini, C.; Dario, P. Jumping like an insect: Design and dynamic optimization of a jumping mini robot based on bio-mimetic inspiration. Mechatronics 2012, 22, 167-176. [CrossRef]

39. Picardi, G.; Laschi, C.; Calisti, M. Model-based open loop control of a multigait legged underwater robot. Mechatronics 2018, 55, 162-170. [CrossRef] 
40. Scarfogliero, U.; Li, F.; Chen, D.; Stefanini, C.; Liu, W.; Dario, P. Jumping mini-robot as a model of scale effects on legged locomotion. In Proceedings of the 2007 IEEE International Conference on Robotics and Biomimetics, Sanya, China, 15-18 December 2007; pp. 853-858. [CrossRef]

41. Graichen, K.; Hentzelt, S.; Hildebrandt, A.; Kärcher, N.; Gaißert, N.; Knubben, E. Control design for a bionic kangaroo. Control Eng. Pract. 2015, 42, 106-117. [CrossRef]

42. Sutton, G.P.; Doroshenko, M.; Cullen, D.A.; Burrows, M. Take-off speed in jumping mantises depends on body size and a power-limited mechanism. J. Exp. Biol. 2016, 219, 2127-2136. [CrossRef] [PubMed]

43. Nabawy, M.R.; Sivalingam, G.; Garwood, R.J.; Crowther, W.J.; Sellers, W.I. Energy and time optimal trajectories in exploratory jumps of the spider Phidippus. Regius. Sci. Rep. 2018, 8, 7142. [CrossRef]

44. Ribak, G.; Weihs, D. Jumping without using legs: The jump of the click-beetles (Elateridae) is morphologically constrained. PLoS ONE 2011, 6, e20871. [CrossRef]

45. Christian, V.E. The jump of the springtails. Naturwissenschaften 1978, 65, 495-496. [CrossRef]

46. Burrows, M.; Dorosenko, M. Jumping mechanisms in adult caddisflies (Insecta, Trichoptera). J. Exp. Biol. 2015, 218, 2764-2774. [CrossRef]

47. Burrows, M.; Dorosenko, M. Jumping mechanisms and strategies in moths (Lepidoptera). J. Exp. Biol. 2015, 218, 1655-1666. [CrossRef]

48. Mo, X.; Ge, W.; Romano, D.; Donati, E.; Benelli, G.; Dario, P.; Stefanini, C. Modelling jumping in Locusta migratoria and the influence of substrate roughness. Entomol. Gen. 2019, 38, 317-332. [CrossRef]

49. Developing Flies Jump without Legs. Available online: https://phys.org/news/2018-01-flies-legs.html (accessed on 20 August 2020).

50. This Legless Insect Can Jump 30 Times Its Body Length. Available online: http://www.sciencemag.org/news/ 2018/01/legless-insect-can-jump-30-times-its-body-length (accessed on 20 August 2020).

51. Brown, R.H.J. Mechanism of locust jumping. Nature 1967, 214, 939. [CrossRef]

52. Cofer, D.W.; Reid, J.; Zhu, Y.; Cymbalyuk, G.; Heitler, W.J.; Edwards, D.H. Role of the semi-lunar process in locust jumping. BMC Neurosci. 2007, 8, P12. [CrossRef]

53. Snelling, E.P.; Becker, C.L.; Seymour, R.S. The effects of temperature and body mass on jump performance of the locust Locusta migratoria. PLoS ONE 2013, 8, e72471. [CrossRef]

54. Bennet-Clark, H.C.; Lucey, E.C.A. The jump of the flea: A study of the energetics and a model of the mechanism. J. Exp. Biol. 1967, 47, 59-76. [CrossRef]

55. Sutton, G.P.; Burrows, M. Biomechanics of jumping in the flea. J. Exp. Biol. 2011, 214, 836-847. [CrossRef]

56. Picker, M.D.; Colville, J.F.; Burrows, M. A cockroach that jumps. Biol. Lett. 2012, 8, 390-392. [CrossRef]

57. Bohn, H.; Picker, M.; Klass, K.; Colville, J. A jumping cockroach from South Africa. Saltoblattella montistabularis, gen. nov., spec. nov. (Blattodea: Blattellidae). Arthropod. Syst. Phylogeny 2010, 68, 53-69. [CrossRef]

58. Tauber, E.R.A.N.; Camhi, J. The wind-evoked escape behavior of the cricket Gryllus bimaculatus: Integration of behavioral elements. J. Exp. Biol. 1995, 198, 1895-1907.

59. Burrows, M. Jumping performance of froghopper insects. J. Exp. Biol. 2006, 209, 4607-4621. [CrossRef]

60. Burrows, M. Morphology and action of the hind leg joints controlling jumping in froghopper insects. J. Exp. Biol. 2006, 209, 4622-4637. [CrossRef] [PubMed]

61. Burrows, M. Kinematics of jumping in leafhopper insects (Hemiptera, Auchenorrhyncha, Cicadellidae). J. Exp. Biol. 2007, 210, 3579-3589. [CrossRef] [PubMed]

62. Burrows, M. Anatomy of the hind legs and actions of their muscles during jumping in leafhopper insects. J. Exp. Biol. 2007, 210, 3590-3600. [CrossRef]

63. Bonsignori, G.; Stefanini, C.; Scarfogliero, U.; Mintchev, S.; Benelli, G.; Dario, P. The green leafhopper, Cicadella viridis (Hemiptera, Auchenorrhyncha, Cicadellidae), jumps with near-constant acceleration. J. Exp. Biol. 2013, 216, 1270-1279. [CrossRef]

64. Burrows, M. Jumping strategies and performance in shore bugs (Hemiptera, Heteroptera, Saldidae). J. Exp. Biol. 2009, 212, 106-115. [CrossRef]

65. Burrows, M.; Morris, O. Jumping and kicking in bush crickets. J. Exp. Biol. 2003, 206, 1035-1049. [CrossRef]

66. Chen, Y.; Liao, C.; Tsai, F.; Chi, K. More than a safety line: Jump-stabilizing silk of salticids. J. R. Soc. Interface 2013, 10, 20130572. [CrossRef]

67. Weihmann, T.; Karner, M.; Full, R.J.; Blickhan, R. Jumping kinematics in the wandering spider Cupiennius salei. J. Comp. Physiol. A 2010, 196, 421-438. [CrossRef] 
68. Parry, D.A.; Brown, R.H.J. The jumping mechanism of salticid spiders. J. Exp. Biol. 1959, 36, 654-664. [CrossRef]

69. Evans, M.E.G. The jump of the click beetle (Coleoptera, Elateridae)-A preliminary study. J. Zool. 1972, 167, 319-336. [CrossRef]

70. Evans, M.E.G. The jump of the click beetle (Coleoptera: Elateridae)—Energetics and mechanics. J. Zool. 1973, 169, 181-194. [CrossRef]

71. Bolmin, O.; Duan, C.; Urrutia, L.; Abdulla, A.M.; Hazel, A.M.; Alleyne, M.; Dunn, A.C.; Wissa, A. Pop! Observing and Modeling the Legless Self-righting Jumping Mechanism of Click Beetles. In Proceedings of the Conference on Biomimetic and Biohybrid Systems, Stanford, CA, USA, 26-28 July 2017; pp. 35-47. [CrossRef]

72. Brackenbury, J.; Hunt, H. Jumping in springtails: Mechanism and dynamics. J. Zool. 1993, 229, $217-236$. [CrossRef]

73. Faraji, H.; Tachella, R.; Hatton, R.L. Aiming and vaulting: Spider inspired leaping for jumping robots. In Proceedings of the 2016 IEEE International Conference on Robotics and Automation, Stockholm, Sweden, 16-21 May 2016; pp. 2082-2087. [CrossRef]

74. Tachella, R. Design and Development of a Salticid Inspired Jumping Robot. Master's Thesis, Oregon State University, Corvallis, OR, USA, 2016.

75. Hill, D.E. Targeted Jumps by Salticid Spiders (Araneae, Salticidae, Phidippus), Version 9; Peckhamia Epublications: 2006; pp. 1-28.

76. Spröwitz, A.; Göttler, C.; Sinha, A.; Caer, C.; Öoztekin, M.U.; Petersen, K.; Sitti, M. Scalable pneumatic and tendon driven robotic joint inspired by jumping spiders. In Proceedings of the 2017 IEEE International Conference on Robotics and Automation, Singapore, 29 May-3 June 2017; pp. 64-70. [CrossRef]

77. Zhu, Y.; Chen, L.; Liu, Q.; Qin, R.; Jin, B. Omnidirectional Jump of a Legged Robot Based on the Behavior Mechanism of a Jumping Spider. Appl. Sci. 2018, 8, 51. [CrossRef]

78. Shield, S.; Fisher, C.; Patel, A. A spider-inspired dragline enables aerial pitch righting in a mobile robot. In Proceedings of the 2015 IEEE/RSJ International Conference on Intelligent Robots and Systems, Hamburg, Germany, 28 September-2 October 2015; pp. 319-324. [CrossRef]

79. Albrecht, F.O. The Anatomy of the Migratory Locust; The Athlone Press: London, UK, 1953.

80. Mo, X.; Romano, D.; Miraglia, M.; Ge, W.; Stefanini, C. Effect of substrates' compliance on the jumping mechanism of Locusta migratoria. Front. Bioeng. Biotechnol. 2020, 8, 661. [CrossRef]

81. Romano, D.; Bloemberg, J.; Tannous, M.; Stefanini, C. Impact of aging and cognitive mechanisms on high-speed motor activation patterns: Evidence from an orthoptera-robot interaction. IEEE Trans. Med. Robot. Bionics 2020, 2, 292-296. [CrossRef]

82. Mo, X.; Romano, D.; Milazzo, M.; Benelli, G.; Stefanini, C. Impact of different developmental instars on Locusta migratoria jumping performance. Appl. Bionics Biomech. 2020, 2020, 1-11. [CrossRef]

83. Han, L.; Wang, Z.; Ji, A.; Dai, Z. The mechanics and trajectory control in locust jumping. J. Bionic Eng. 2013, 10, 194-200. [CrossRef]

84. Chen, D.; Yin, J.; Chen, K.; Li, Z. Biomechanical and dynamic mechanism of locust take-off. Acta Mech. Sin. 2014, 30, 762-774. [CrossRef]

85. Heitler, W.J. The locust jump: III. Structural specializations of the metathoracic tibiae. J. Exp. Biol. 1977, 67, 29-36.

86. Heitler, W.J. Locust jump. Specialisations of the metathoracic femoral-tibial joint. J. Comp. Physiol. 1974, 89, 93-104. [CrossRef]

87. Heitler, W.J.; Burrows, M. The locust jump. I. The motor programme. J. Exp. Biol. 1977, 66, $203-219$.

88. Kovac, M.; Fuchs, M.; Guignard, A.; Zufferey, J.C.; Floreano, D. A miniature 7 g jumping robot. In Proceedings of the 2008 IEEE International Conference on Robotics and Automation, Pasadena, CA, USA, 19-23 May 2008; pp. 373-378. [CrossRef]

89. Kovac, M. Bioinspired Jumping Locomotion for Miniature Robotics. Ph.D. Thesis, Swiss Federal Institute of Technology in Lausanne, Lausanne, Switzerland, 2010. [CrossRef]

90. Kovač, M.; Schlegel, M.; Zufferey, J.C.; Floreano, D. A miniature jumping robot with self-recovery capabilities. In Proceedings of the 2009 IEEE/RSJ International Conference on Intelligent Robots and Systems, St. Louis, MO, USA, 10-15 October 2009; pp. 583-588. [CrossRef] 
91. Vidyasagar, A.; Zufferey, J.C.; Floreano, D.; Kovač, M. Performance analysis of jump-gliding locomotion for miniature robotics. Bioinspir. Biomim. 2015, 10, 025006. [CrossRef]

92. Kovač, M.; Fauria, O.; Zufferey, J.C.; Floreano, D. The EPFL jumpglider: A hybrid jumping and gliding robot with rigid or folding wings. In Proceedings of the 2011 IEEE International Conference on Robotics and Biomimetics, Phuket, Thailand, 7-11 December 2011; pp. 1503-1508. [CrossRef]

93. Kovač, M.; Fauria, O.; Zufferey, J.C.; Floreano, D. The locomotion capabilities of the EPFL jumpglider: A hybrid jumping and gliding robot. In Proceedings of the 2011 IEEE International Conference on Robotics and Biomimetics, Phuket, Thailand, 7-11 December 2011; pp. 2249-2250. [CrossRef]

94. Kovač, M.; Schlegel, M.; Zufferey, J.C.; Floreano, D. Steerable miniature jumping robot. Auton. Robot. 2010, 28, 295-306. [CrossRef]

95. Zaitsev, V.; Gvirsman, O.; Ben-Hanan, U.; Weiss, A.; Ayali, A.; Kósa, G. Locust-inspired miniature jumping robot. In Proceedings of the 2015 IEEE/RSJ International Conference on Intelligent Robots and Systems, Hamburg, Germany, 28 September-2 October 2015; pp. 553-558. [CrossRef]

96. Zaitsev, V.; Gvirsman, O.; Hanan, U.B.; Weiss, A.; Ayali, A.; Kosa, G. A locust-inspired miniature jumping robot. Bioinspir. Biomim. 2015, 10, 066012. [CrossRef]

97. Hanan, U.B.; Weiss, A.; Zaitsev, V. Jumping efficiency of small creatures and its applicability in robotics. Procedia Manuf. 2018, 21, 243-250. [CrossRef]

98. Beck, A.; Zaitsev, V.; Hanan, U.B.; Kosa, G.; Ayali, A.; Weiss, A. Jump stabilization and landing control by wing-spreading of a locust-inspired jumper. Bioinspir. Biomim. 2017, 12, 066006. [CrossRef]

99. Weiss, A.; Zaitsev, V.; Nabi, N.; Ben-Hanan, U. Landing recovery and orientation control of a locust-inspired miniature jumping robot. Eng. Res. Express 2020, 2, 015017. [CrossRef]

100. Nguyen, Q.V.; Park, H.C. Design and demonstration of a locust-like jumping mechanism for small-scale robots. J. Bionic Eng. 2012, 9, 271-281. [CrossRef]

101. Zhang, J.; Song, G.; Li, Y.; Qiao, G.; Song, A.; Wang, A. A bio-inspired jumping robot: Modeling, simulation, design, and experimental results. Mechatronics 2013, 23, 1123-1140. [CrossRef]

102. Zhang, J.; Song, G.; Qiao, G.; Li, Z.; Wang, W.; Song, A. A novel one-motor driven robot that jumps and walks. In Proceedings of the 2013 IEEE International Conference on Robotics and Automation, Karlsruhe, Germany, 6-10 May 2013; pp. 13-19. [CrossRef]

103. Zhang, J.; Zhu, Y.; Wang, H.; Zhang, J. Design of a bio-inspired jumping robot for rough terrain. In Proceedings of the 2010 International Conference on Environmental Science and Information Application Technology, Wuhan, China, 17-18 July 2010; pp. 40-43. [CrossRef]

104. Zhang, J.; Song, G.; Li, Z.; Qiao, G.; Sun, H.; Song, A. Self-righting, steering and take-off angle adjusting for a jumping robot. In Proceedings of the 2012 IEEE/RSJ International Conference on Intelligent Robots and Systems, Vilamoura, Portugal, 7-12 October 2012; pp. 2089-2094. [CrossRef]

105. Zhang, J.; Song, G.; Qiao, G.; Li, Z.; Wang, A. A wireless sensor network system with a jumping node for unfriendly environments. Int. J. Distrib. Sens. Netw. 2012, 8, 568240. [CrossRef]

106. Zhang, J.; Song, G.; Qiao, G.; Meng, T.; Sun, H. An indoor security system with a jumping robot as the surveillance terminal. IEEE Trans. Consum. Electr. 2011, 57, 1774-1781. [CrossRef]

107. Chen, D.; Yin, J.; Huang, Y.; Zhao, K.; Wang, T. A hopping-righting mechanism analysis and design of the mobile robot. J. Braz. Soc. Mech. Sci. Eng. 2013, 35, 469-478. [CrossRef]

108. Chen, D.; Yin, J.; Zhao, K.; Zheng, W.; Wang, T. Bionic mechanism and kinematics analysis of hopping robot inspired by locust jumping. J. Bionic Eng. 2011, 8, 429-439. [CrossRef]

109. Chen, D.S.; Zhang, Z.Q.; Chen, K.W. Dynamic model and performance analysis of landing buffer for bionic locust mechanism. Acta Mech. Sin. 2016, 32, 551-565. [CrossRef]

110. Chen, D.; Zhang, Z.; Chen, K. Legs attitudes determination for bionic locust robot based on landing buffering performance. Mech. Mach. Theory 2016, 99, 117-139. [CrossRef]

111. Chen, D.; Chen, K.; Zhang, Z.; Zhang, B. Mechanism of locust air posture adjustment. J. Bionic Eng. 2015, 12, 418-431. [CrossRef]

112. Chen, D.; Yin, J.; Chen, K.; Zhao, K.; Zhang, B. Prototype design and experimental study on locust air-posture righting. J. Bionic Eng. 2014, 11, 459-468. [CrossRef]

113. Zhang, Z.; Yang, Q.; Gui, S.; Chang, B.; Zhao, J.; Yang, H.; Chen, D. Mechanism design for locust-inspired robot with one-DOF leg based on jumping stability. Mech. Mach. Theory 2019, 133, 584-605. [CrossRef] 
114. Cadiergues, M.C.; Joubert, C.; Franc, M. A comparison of jump performances of the dog flea, Ctenocephalides canis (Curtis, 1826) and the cat flea, Ctenocephalides felis (Bouché, 1835). Vet. Parasitol. 2000, 92, 239-241. [CrossRef]

115. Rothschild, M.; Schlein, J. The jumping mechanism of Xenopsylla cheopis. I. exoskeletal structures and musculature. Philos. Trans. R. Soc. Lond. B Biol. Sci. 1975, 271, 457-490. [CrossRef]

116. Cullen, M.J. The jumping mechanism of Xenopsylla cheopis II. The fine structure of the jumping muscle. Philos. Trans. R. Soc. Lond. B Biol. Sci. 1975, 271, 491-497. [CrossRef] [PubMed]

117. Rothschild, M.L.; Schlein, J.; Parker, K.; Neville, C.; Sternberg, S. The jumping mechanism of Xenopsylla cheopis III. Execution of the jump and activity. Philos. Trans. R. Soc. Lond. B Biol. Sci. 1975, 271, 499-515. [CrossRef] [PubMed]

118. Noh, M.; Kim, S.W.; An, S.; Koh, J.S.; Cho, K.J. Flea-inspired catapult mechanism for miniature jumping robots. IEEE Trans. Robot. 2012, 28, 1007-1018. [CrossRef]

119. Jung, G.P.; Kim, J.S.; Koh, J.S.; Jung, S.P.; Cho, K.J. Role of compliant leg in the flea-inspired jumping mechanism. In Proceedings of the 2014 IEEE/RSJ International Conference on Intelligent Robots and Systems, Chicago, IL, USA, 14-18 September 2014; pp. 315-320. [CrossRef]

120. Jung, G.P.; Choi, H.C.; Cho, K.J. The effect of leg compliance in multi-directional jumping of a flea-inspired mechanism. Bioinspir. Biomim. 2017, 12, 026006. [CrossRef] [PubMed]

121. Koh, J.S.; Jung, S.P.; Wood, R.J.; Cho, K.J. A jumping robotic insect based on a torque reversal catapult mechanism. In Proceedings of the 2013 IEEE/RSJ International Conference on Intelligent Robots and Systems, Tokyo, Japan, 3-7 November 2013; pp. 3796-3801. [CrossRef]

122. Jung, S.P.; Jung, G.P.; Koh, J.S.; Lee, D.Y.; Cho, K.J. Fabrication of Composite and Sheet Metal Laminated Bistable Jumping Mechanism. J. Mech. Robot. 2015, 7, 021010. [CrossRef]

123. Koh, J.S.; Jung, S.P.; Noh, M.; Kim, S.W.; Cho, K.J. Flea inspired catapult mechanism with active energy storage and release for small scale jumping robot. In Proceedings of the 2013 IEEE International Conference on Robotics and Automation, Karlsruhe, Germany, 6-10 May 2013; pp. 26-31. [CrossRef]

124. Urban Hopper. Available online: https://www.sandia.gov/research/robotics/unique_mobility/urban_hopper. html (accessed on 20 August 2020).

125. Ackerman, E. Boston dynamics sand flea robot demonstrates astonishing jumping skills. IEEE Spectr. Robot. Blog. 2012, 2.

126. Laksanacharoen, S.; Pollack, A.J.; Nelson, G.M.; Quinn, R.D.; Ritzmann, R.E. Biomechanics and simulation of cricket for microrobot design. In Proceedings of the IEEE International Conference on Robotics and Automation, San Francisco, CA, USA, 24-28 April 2000; Volume 2, pp. 1088-1094. [CrossRef]

127. Birch, M.C.; Quinn, R.D.; Hahm, G.; Phillips, S.M.; Drennan, B.; Fife, A.; Verma, H.; Beer, R.D. Design of a cricket microrobot. In Proceedings of the IEEE International Conference on Robotics and Automation, San Francisco, CA, USA, 24-28 April 2000; Volume 2, pp. 1109-1114. [CrossRef]

128. Birch, M.C.; Quinn, R.D.; Hahm, G.; Phillips, S.M.; Drennan, B.T.; Fife, A.J.; Pollack, A.J.; Beer, R.; Yu, X.; Garverick, S.; et al. Cricket-based robots. IEEE Robot. Autom. Mag. 2002, 9, 20-30. [CrossRef]

129. Allen, T.J.; Quinn, R.D.; Bachmann, R.J.; Ritzmann, R.E. Abstracted biological principles applied with reduced actuation improve mobility of legged vehicles. In Proceedings of the 2003 IEEE/RSJ International Conference on Intelligent Robots and Systems, Las Vegas, NV, USA, 27-31 October 2003; Volume 2, pp. 1370-1375. [CrossRef]

130. Lambrecht, B.G.; Horchler, A.D.; Quinn, R.D. A small, insect-inspired robot that runs and jumps. In Proceedings of the 2005 IEEE International Conference on Robotics and Automation, Barcelona, Spain, 18-22 April 2005; pp. 1240-1245. [CrossRef]

131. Jayaram, K.; Full, R.J. Cockroaches traverse crevices, crawl rapidly in confined spaces, and inspire a soft, legged robot. Proc. Natl. Acad. Sci. USA 2016, 113, 950-957. [CrossRef]

132. HAMR: Versatile Crawling Microrobot. Available online: https://wyss.harvard.edu/technology/versatileambulatory-microrobots/ (accessed on 20 August 2020).

133. Chen, Y.; Doshi, N.; Goldberg, B.; Wang, H.; Wood, R.J. Controllable water surface to underwater transition through electrowetting in a hybrid terrestrial-aquatic microrobot. Nat. Commun. 2018, 9, 2495. [CrossRef]

134. Sutton, G.P.; Burrows, M. The mechanics of azimuth control in jumping by froghopper insects. J. Exp. Biol. 2010, 213, 1406-1416. [CrossRef] 
135. Jung, G.P.; Cho, K.J. Froghopper-inspired direction-changing concept for miniature jumping robots. Bioinspir. Biomim. 2016, 11, 056015. [CrossRef]

136. Scarfogliero, U.; Stefanini, C.; Dario, P. A bioinspired concept for high efficiency locomotion in micro robots: The jumping robot grillo. In Proceedings of the 2006 IEEE International Conference on Robotics and Automation, Orlando, FL, USA, 15-19 May 2006; pp. 4037-4042. [CrossRef]

137. Scarfogliero, U.; Stefanini, C.; Dario, P. Design and Development of the Long-Jumping “Grillo" Mini Robot. In Proceedings of the 2007 IEEE International Conference on Robotics and Automation, Roma, Italy, 10-14 April 2007; pp. 467-472. [CrossRef]

138. Li, F.; Bonsignori, G.; Scarfogliero, U.; Chen, D.; Stefanini, C.; Liu, W.; Dario, P.; Fu, X. Jumping mini-robot with bio-inspired legs. In Proceedings of the IEEE International Conference on Robotics and Biomimetics, Bangkok, Thailand, 22-25 February 2009; pp. 933-938. [CrossRef]

139. Marsh, R.L.; John-Alder, H.B. Jumping performance of hylid frogs measured with high-speed cine film. J. Exp. Biol. 1994, 188, 131-141. [CrossRef]

140. Azizi, E.; Roberts, T.J. Muscle performance during frog jumping: Influence of elasticity on muscle operating lengths. Proc. R. Soc. B Biol. Sci. 2010, 277, 1523-1530. [CrossRef]

141. Astley, H.C.; Roberts, T.J. Evidence for a vertebrate catapult: Elastic energy storage in the plantaris tendon during frog jumping. Biol. Lett. 2011, 8, 386-389. [CrossRef]

142. Astley, H.C.; Roberts, T.J. The mechanics of elastic loading and recoil in anuran jumping. J. Exp. Biol. 2014, 217, 4372-4378. [CrossRef]

143. Wang, M.; Zang, X.Z.; Fan, J.Z.; Zhao, J. Biological jumping mechanism analysis and modeling for frog robot. J. Bionic Eng. 2008, 5, 181-188. [CrossRef]

144. Zhong, J.; Luo, M.; Liu, X.; Fan, J.; Zhao, J. Frog-inspired jumping robot actuated by pneumatic muscle actuators. Adv. Mech. Eng. 2018, 10, 1687814018782303. [CrossRef]

145. Fiorini, P.; Hayati, S.; Heverly, M.; Gensler, J. A hopping robot for planetary exploration. In Proceedings of the IEEE Aerospace Conference, Aspen, CO, USA, 7 March 1999; Volume 2, pp. 153-158. [CrossRef]

146. Fiorini, P.; Burdick, J. The development of hopping capabilities for small robots. Auton. Robot. 2003, 14, 239-254. [CrossRef]

147. Ahn, J.; Park, J.; Kim, K.S.; Kim, S. Frog-inspired jumping robot for overcoming high obstacles. In Proceedings of the 2013 IEEE International Symposium on Robotics, Seoul, South Korea, 24-26 October 2013; pp. 1-4. [CrossRef]

148. Jung, G.P.; Casarez, C.S.; Jung, S.P.; Fearing, R.S.; Cho, K.J. An integrated jumping-crawling robot using height-adjustable jumping module. In Proceedings of the 2016 IEEE International Conference on Robotics and Automation, Stockholm, Sweden, 16-21 May 2016; pp. 4680-4685. [CrossRef]

149. Yim, S.; Baek, S.M.; Jung, G.P.; Cho, K.J. An Omnidirectional Jumper with Expanded Movability via Steering, Self-Righting and Take-off Angle Adjustment. In Proceedings of the 2018 IEEE/RSJ International Conference on Intelligent Robots and Systems, Madrid, Spain, 1-5 October 2018; pp. 416-421. [CrossRef]

150. Woodward, M.A.; Sitti, M. Design of a miniature integrated multi-modal jumping and gliding robot. In Proceedings of the 2011 IEEE/RSJ International Conference on Intelligent Robots and Systems, San Francisco, CA, USA, 25-30 September 2011; pp. 556-561. [CrossRef]

151. Woodward, M.A.; Sitti, M. Multimo-bat: A biologically inspired integrated jumping-gliding robot. Int. J. Robot. Res. 2014, 33, 1511-1529. [CrossRef]

152. Woodward, M.A.; Sitti, M. Morphological intelligence counters foot slipping in the desert locust and dynamic robots. Proc. Natl. Acad. Sci. USA 2018, 115, E8358-E8367. [CrossRef]

153. Kim, H.; Woodward, M.A.; Sitti, M. Enhanced Non-Steady Gliding Performance of the MultiMo-Bat through Optimal Airfoil Configuration and Control Strategy. In Proceedings of the 2018 IEEE/RSJ International Conference on Intelligent Robots and Systems, Madrid, Spain, 1-5 October 2018; pp. 1382-1388. [CrossRef]

154. Alexander, R.M. Tendon elasticity and muscle function. Comp. Biochem. Physiol. A Mol. Integr. Physiol. 2002, 133, 1001-1011. [CrossRef]

155. Hall-Crags, E.C.B. An analysis of the jump of the lesser galago (Galago senegalensis). In Proceedings of the Zoological Society of London; Blackwell Publishing Ltd.: Oxford, UK, 1965; Volume 147, pp. 20-29. [CrossRef]

156. Aerts, P. Vertical jumping in Galago senegalensis: The quest for an obligate mechanical power amplifier. Philos. Trans. R. Soc. Lond. B Biol. Sci. 1998, 353, 1607-1620. [CrossRef] 
157. Haldane, D.W.; Plecnik, M.; Yim, J.K.; Fearing, R.S. A power modulating leg mechanism for monopedal hopping. In Proceedings of the 2016 IEEE/RSJ International Conference on Intelligent Robots and Systems, Daejeon, Korea, 9-14 October 2016; pp. 4757-4764. [CrossRef]

158. Haldane, D.W.; Plecnik, M.M.; Yim, J.K.; Fearing, R.S. Robotic vertical jumping agility via series-elastic power modulation. Sci. Robot. 2016, 1, eaag2048. [CrossRef]

159. Plecnik, M.M.; Haldane, D.W.; Yim, J.K.; Fearing, R.S. Design exploration and kinematic tuning of a power modulating jumping monopod. J. Mech. Robot. 2017, 9, 011009. [CrossRef]

160. Haldane, D.W.; Yim, J.K.; Fearing, R.S. Repetitive extreme-acceleration (14-g) spatial jumping with Salto-1P. In Proceedings of the 2017 IEEE/RSJ International Conference on Intelligent Robots and Systems, Vancouver, BC, Canada, 24-28 September 2017; pp. 3345-3351. [CrossRef]

161. Yim, J.K.; Fearing, R.S. Precision Jumping Limits from Flight-phase Control in Salto-1P. In Proceedings of the 2018 IEEE/RSJ International Conference on Intelligent Robots and Systems, Madrid, Spain, 1-5 October 2018; pp. 2229-2236. [CrossRef]

162. Why Is Australia so Hopping Mad? Available online: https://www.australiangeographic.com.au/blogs/wildjourney/2016/11/why-do-australian-animals-hop/ (accessed on 20 August 2020).

163. McGowan, C.P.; Collins, C.E. Why do mammals hop? Understanding the ecology, biomechanics and evolution of bipedal hopping. J. Exp. Biol. 2018, 221, jeb161661. [CrossRef]

164. Dawson, T.J.; Taylor, C.R. Energetic cost of locomotion in kangaroos. Nature 1973, 246, 313. [CrossRef]

165. Alexander, R.M.; Vernon, A. The mechanics of hopping by kangaroos (Macropodidae). J. Zool. 1975, 177, 265-303. [CrossRef]

166. Bennett, M.B. Fast locomotion of some kangaroos. J. Zool. 1987, 212, 457-464. [CrossRef]

167. Festo's Newest Robot Is a Hopping Bionic Kangaroo. Available online: https:/spectrum.ieee.org/automaton/ robotics/robotics-hardware/festo-newest-robot-is-a-hopping-bionic-kangaroo (accessed on 20 August 2020).

168. Liu, G.H.; Lin, H.Y.; Lin, H.Y.; Chen, S.T.; Lin, P.C. Design of a kangaroo robot with dynamic jogging locomotion. In Proceedings of the 2013 IEEE/SICE International Symposium on System Integration, Kobe, Japan, 15-17 December 2013; pp. 306-311. [CrossRef]

169. Liu, G.H.; Lin, H.Y.; Lin, H.Y.; Chen, S.T.; Lin, P.C. A bio-inspired hopping kangaroo robot with an active tail. J. Bionic Eng. 2014, 11, 541-555. [CrossRef]

170. Jun, B.R.; Kim, Y.J.; Jung, S. Design and control of jumping mechanism for a Kangaroo-inspired robot. In Proceedings of the 2016 6th IEEE International Conference on Biomedical Robotics and Biomechatronics, Singapore, 26-29 June 2016; pp. 436-440. [CrossRef]

171. Spägele, T.; Kistner, A.; Gollhofer, A. Modelling, simulation and optimisation of a human vertical jump. J. Biomech. 1999, 32, 521-530. [CrossRef]

172. Niiyama, R.; Nagakubo, A.; Kuniyoshi, Y. Mowgli: A bipedal jumping and landing robot with an artificial musculoskeletal system. In Proceedings of the 2007 IEEE International Conference on Robotics and Automation, Roma, Italy, 10-14 April 2007; pp. 2546-2551. [CrossRef]

173. Niiyama, R.; Kuniyoshi, Y. A pneumatic biped with an artificial musculoskeletal system. In Proceedings of the 4th International Symposium on Adaptive Motion of Animals and Machines, Cleveland, OH, USA, 1-6 June 2008; pp. 80-81.

174. Niiyama, R.; Kuniyoshi, Y. Design principle based on maximum output force profile for a musculoskeletal robot. Ind. Robot. Int. J. 2010, 37, 250-255. [CrossRef]

175. Boston Dynamics' Humanoid Robot Can Now Jump Upstairs Like a Parkour Pro. Available online: https://www. businessinsider.com/boston-dynamics-atlas-robot-do-parkour-2018-10?IR=T (accessed on 20 August 2020).

176. Parkour Atlas. Available online: https://www.youtube.com/watch?v=LikxFZZO2sk (accessed on 20 August 2020).

177. Hyon, S.H.; Mita, T. Development of a biologically inspired hopping robot— “Kenken”. In Proceedings of the 2002 IEEE International Conference on Robotics and Automation, Washington, DC, USA, 11-15 May 2002; Volume 4, pp. 3984-3991. [CrossRef]

178. Hyon, S.H.; Emura, T.; Mita, T. Dynamics-based control of a one-legged hopping robot. Proc. Inst. Mech. Eng. Part I J. Syst. Control Eng. 2003, 217, 83-98. [CrossRef]

179. Koh, J.S.; Yang, E.; Jung, G.P.; Jung, S.P.; Son, J.H.; Lee, S.I.; Jablonski, P.G.; Wood, R.J.; Kim, H.Y.; Cho, K.J. Jumping on water: Surface tension-dominated jumping of water striders and robotic insects. Science 2015, 349, 517-521. [CrossRef]

180. Burrows, M.; Sutton, G.P. Pygmy mole crickets jump from water. Curr. Biol. 2012, 22, 990-991. [CrossRef] 
181. Burrows, M. Jumping from the surface of water by the long-legged fly Hydrophorus (Diptera, Dolichopodidae). J. Exp. Biol. 2013, 216, 1973-1981. [CrossRef]

182. Shih, A.M.; Mendelson, L.; Techet, A.H. Archer fish jumping prey capture: Kinematics and hydrodynamics. J. Exp. Biol. 2017, 220, 1411-1422. [CrossRef]

183. Martinez, M.M.; Full, R.J.; Koehl, M.A. Underwater punting by an intertidal crab: A novel gait revealed by the kinematics of pedestrian locomotion in air versus water. J. Exp. Biol. 1998, 201, 2609-2623.

184. Nauwelaerts, S.; Scholliers, J.; Aerts, P. A functional analysis of how frogs jump out of water. Biol. J. Linn. Soc. 2004, 83, 413-420. [CrossRef]

185. Bush, J.W.; Hu, D.L. Walking on Water: Biolocomotion at the Interface. Annu. Rev. Fluid Mech. 2006, 38, 339-369. [CrossRef]

186. Glasheen, J.W.; McMahon, T.A. A hydrodynamic model of locomotion in the basilisk lizard. Nature 1996, 380, 340. [CrossRef]

187. Hsieh, S.T.; Lauder, G.V. Running on water: Three-dimensional force generation by basilisk lizards. Proc. Natl. Acad. Sci. USA 2004, 101, 16784-16788. [CrossRef]

188. Burrows, M.; Picker, M.D. Jumping mechanisms and performance of pygmy mole crickets (Orthoptera, Tridactylidae). J. Exp. Biol. 2010, 213, 2386-2398. [CrossRef]

189. Dewenter, J.; Gerullis, P.; Hecker, A.; Schuster, S. Archerfish use their shooting technique to produce adaptive underwater jets. J. Exp. Biol. 2017, 220, 1019-1025. [CrossRef]

190. Shih, A.M.; Techet, A.H. Characterization of the jumping behavior of archer fish, Toxotes Microlepis. In Proceedings of the 6th World Congress of Biomechanics (WCB 2010), Singapore, 1-6 August 2010. [CrossRef]

191. Feng, X.Q.; Gao, X.; Wu, Z.; Jiang, L.; Zheng, Q.S. Superior water repellency of water strider legs with hierarchical structures: Experiments and analysis. Langmuir 2007, 23, 4892-4896. [CrossRef]

192. Shi, F.; Niu, J.; Liu, J.; Liu, F.; Wang, Z.; Feng, X.Q.; Zhang, X. Towards understanding why a superhydrophobic coating is needed by water striders. Adv. Mater. 2007, 19, 2257-2261. [CrossRef]

193. Song, Y.S.; Sitti, M. Surface-tension-driven biologically inspired water strider robots: Theory and experiments. IEEE Trans. Robot. 2007, 23, 578-589. [CrossRef]

194. Shin, B.; Kim, H.Y.; Cho, K.J. Towards a biologically inspired small-scale water jumping robot. In Proceedings of the 2008 IEEE RAS \& EMBS International Conference on Biomedical Robotics and Biomechatronics, Scottsdale, AZ, USA, 19-22 October 2008; pp. 127-131. [CrossRef]

195. Zhang, X.; Zhao, J.; Zhu, Q.; Chen, N.; Zhang, M.; Pan, Q. Bioinspired aquatic microrobot capable of walking on water surface like a water strider. ACS Appl. Mater. Interfaces 2011, 3, 2630-2636. [CrossRef]

196. Zhao, J.; Zhang, X.; Chen, N.; Pan, Q. Why superhydrophobicity is crucial for a water-jumping microrobot? Experimental and theoretical investigations. ACS Appl. Mater. Interfaces 2012, 4, 3706-3711. [CrossRef]

197. Yan, J.; Yang, K.; Wang, T.; Zhang, X.; Zhao, J. A continuous jumping robot on water mimicking water striders. In Proceedings of the 2016 IEEE International Conference on Robotics and Automation, Stockholm, Sweden, 16-21 May 2016; pp. 4686-4691. [CrossRef]

198. Jiang, F.; Zhao, J.; Kota, A.K.; Xi, N.; Mutka, M.W.; Xiao, L. A miniature water surface jumping robot. IEEE Robot. Autom. Lett. 2017, 2, 1272-1279. [CrossRef]

199. Yu, J.; Su, Z.; Wu, Z.; Tan, M. Development of a fast-swimming dolphin robot capable of leaping. IEEE/ASME Trans. Mechatron. 2016, 21, 2307-2316. [CrossRef]

200. How to Get a Robot to Jump Out of Water. Available online: https://www.electronicsweekly.com/news/ research-news/get-robot-jump-water-2018-11/ (accessed on 20 August 2020).

201. Yu, J.; Su, Z.; Wu, Z.; Tan, M. An integrative control method for bio-inspired dolphin leaping: Design and experiments. IEEE Trans. Ind. Electron. 2016, 63, 3108-3116. [CrossRef]

202. Zufferey, R.; Ancel, A.O.; Farinha, A.; Siddall, R.; Kovac, M. Consecutive aquatic jump-gliding with water-reactive fuel. Sci. Robot. 2019, 4, eaax7330. [CrossRef]

203. Siddall, R.; Kovac, M. Fast aquatic escape with a jet thruster. IEEE-ASME Trans. Mech. 2017, 22, $217-226$. [CrossRef]

204. Chen, Y.; Wang, H.; Helbling, E.F.; Jafferis, N.T.; Zufferey, R.; Ong, A.; Ma, K.; Gravish, N.; Chirarattananon, P.; Kovac, M.; et al. A biologically inspired, flapping-wing, hybrid aerial-aquatic microrobot. Sci. Robot. 2017, 2, eaao5619. [CrossRef] 
205. Siddall, R.; Kovač, M. Launching the AquaMAV: Bioinspired design for aerial-aquatic robotic platforms. Bioinspir. Biomim. 2014, 9, 031001. [CrossRef]

206. Calisti, M.; Falotico, E.; Laschi, C. Hopping on uneven terrains with an underwater one-legged robot. IEEE Robot. Autom. Lett. 2016, 1, 461-468. [CrossRef]

207. Calisti, M.; Laschi, C. Morphological and control criteria for self-stable underwater hopping. Bioinspir. Biomim. 2017, 13, 016001. [CrossRef]

208. Romano, D.; Benelli, G.; Stefanini, C. Escape and surveillance asymmetries in locusts exposed to a Guinea fowl-mimicking robot predator. Sci. Rep. 2017, 7, 12825. [CrossRef]

209. Romano, D.; Benelli, G.; Stefanini, C. Encoding lateralization of jump kinematics and eye use in a locust via bio-robotic artifacts. J. Exp. Biol. 2019, 222, jeb187427. [CrossRef]

210. Sutton, G.P.; Burrows, M. The mechanics of elevation control in locust jumping. J. Comp. Physiol. A 2008, 194, 557-563. [CrossRef]

211. Chai, H.; Li, J.; Ge, W. Gait Analysis on Bionic Kangaroo-hopping Robot Based on Adjustable Geared Five-linkage Mechanism. Robot 2009, 31. [CrossRef]

212. Santer, R.D.; Yamawaki, Y.; Rind, F.C.; Simmons, P.J. Motor activity and trajectory control during escape jumping in the locust Locusta migratoria. J. Comp. Physiol. A 2005, 191, 965-975. [CrossRef]

213. Simmons, P.J.; Rind, F.C.; Santer, R.D. Escapes with and without preparation: The neuroethology of visual startle in locusts. J. Insect Physiol. 2010, 56, 876-883. [CrossRef]

214. Zhao, J.; Xu, J.; Gao, B.; Xi, N.; Cintron, F.J.; Mutka, M.W.; Xiao, L. MSU jumper: A single-motor-actuated miniature steerable jumping robot. IEEE Trans. Robot 2013, 29, 602-614. [CrossRef]

215. Zhao, J.; Zhao, T.; Xi, N.; Mutka, M.W.; Xiao, L. MSU tailbot: Controlling aerial maneuver of a miniature-tailed jumping robot. IEEE/ASME Trans. Mechatron. 2015, 20, 2903-2914. [CrossRef]

216. Bennet-Clark, H.C. The energetics of the jump of the locust Schistocerca gregaria. J. Exp. Biol. 1975, 63, 53-83. [CrossRef]

217. Burrows, M.; Sutton, G.P. Locusts use a composite of resilin and hard cuticle as an energy store for jumping and kicking. J. Exp. Biol. 2012, 215, 3501-3512. [CrossRef]

218. Frantsevich, L. Righting kinematics in beetles (Insecta: Coleoptera). Arthropod Struct. Dev. 2004, 33, $221-235$. [CrossRef]

219. Warrick, D.R.; Dial, K.P.; Biewener, A.A. Asymmetrical force production in the maneuvering flight of pigeons. Auk 1998, 115, 916-928. [CrossRef]

220. Warrick, D.; Dial, K.P. Kinematic, aerodynamic and anatomical mechanisms in the slow, maneuvering flight of pigeons. J. Exp. Biol. 1998, 201, 655-672.

221. Warrick, D.R.; Bundle, M.W.; Dial, K.P. Bird maneuvering flight: Blurred bodies, clear heads. Integr. Comp. Biol. 2002, 42, 141-148. [CrossRef]

222. Robertson, R.M.; Johnson, A.G. Collision avoidance of flying locusts: Steering torques and behaviour. J. Exp. Biol. 1993, 183, 35-60.

223. Karásek, M.; Muijres, F.T.; De Wagter, C.; Remes, B.D.; de Croon, G.C. A tailless aerial robotic flapper reveals that flies use torque coupling in rapid banked turns. Science 2018, 361, 1089-1094. [CrossRef]

224. Luu, T.; Cheung, A.; Ball, D.; Srinivasan, M.V. Honeybee flight: A novel ‘streamlining' response. J. Exp. Biol. 2011, 214, 2215-2225. [CrossRef]

225. Zanker, J.M. On the mechanism of speed and altitude control in Drosophila melanogaster. Physiol. Entomol. 1988, 13, 351-361. [CrossRef]

226. Weis-Fogh, T. Quick estimates of flight fitness in hovering animals, including novel mechanisms for lift production. J. Exp. Biol. 1973, 59, 169-230.

227. Thomas, A.L. Why do birds have tails? The tail as a drag reducing flap, and trim control. J. Theor. Biol. 1996, 183, 247-253. [CrossRef]

228. Thomas, A.L. On the aerodynamics of birds' tails. Philos. Trans. R. Soc. Lond. B Biol. Sci. 1993, 340, 361-380. [CrossRef]

229. Dyhr, J.P.; Cowan, N.J.; Colmenares, D.J.; Morgansen, K.A.; Daniel, T.L. Autostabilizing airframe articulation: Animal inspired air vehicle control. In Proceedings of the 2012 IEEE Conference on Decision and Control, Maui, HI, USA, 10-13 December 2012; pp. 3715-3720. [CrossRef]

230. Baader, A. The posture of the abdomen during locust flight: Regulation by steering and ventilatory interneurones. J. Exp. Biol. 1990, 151, 109-131. 
231. Santer, R.D.; Simmons, P.J.; Rind, F.C. Gliding behaviour elicited by lateral looming stimuli in flying locusts. J. Comp. Physiol. A 2005, 191, 61-73. [CrossRef]

232. Tucker, V.A. Gliding birds: The effect of variable wing span. J. Exp. Biol. 1987, 133, 33-58. [CrossRef]

233. McGuire, J.A.; Dudley, R. The biology of gliding in flying lizards (genus Draco) and their fossil and extant analogs. Integr. Comp. Biol. 2011, 51, 983-990. [CrossRef]

234. Flaherty, E.A.; Ben-David, M.; Smith, W.P. Quadrupedal locomotor performance in two species of arboreal squirrels: Predicting energy savings of gliding. J. Comp. Physiol. B 2010, 180, 1067-1078. [CrossRef]

235. Byrnes, G.; Lim, N.T.L.; Spence, A.J. Take-off and landing kinetics of a free-ranging gliding mammal, the Malayan colugo (Galeopterus variegatus). Philos Trans. R Soc. Lond. B Biol. Sci. 2008, 275, 1007-1013. [CrossRef]

236. Socha, J.J. Gliding Flight in Chrysopelea: Turning a Snake into a Wing. Integr. Comp. Biol. 2011, 51, 969-982. [CrossRef]

237. Socha, J.J. Kinematics: Gliding flight in the paradise tree snake. Nature 2002, 418, 603. [CrossRef]

238. Socha, J.J.; Jafari, F.; Munk, Y.; Byrnes, G. How animals glide: From trajectory to morphology. Can. J. Zool. 2015, 93, 901-924. [CrossRef]

239. Bishop, K.L. Aerodynamic force generation, performance and control of body orientation during gliding in sugar gliders (Petaurus breviceps). J. Exp. Biol. 2007, 210, 2593-2606. [CrossRef]

240. Paskins, K.E.; Bowyer, A.; Megill, W.M.; Scheibe, J.S. Take-off and landing forces and the evolution of controlled gliding in northern flying squirrels Glaucomys sabrinus. J. Exp. Biol. 2007, 210, 1413-1423. [CrossRef]

241. Bahlman, J.W.; Swartz, S.M.; Riskin, D.K.; Breuer, K.S. Glide performance and aerodynamics of non-equilibrium glides in northern flying squirrels (Glaucomys sabrinus). J. R. Soc. Interface 2013, 10, 20120794. [CrossRef]

242. Socha, J.J.; Miklasz, K.; Jafari, F.; Vlachos, P.P. Non-equilibrium trajectory dynamics and the kinematics of gliding in a flying snake. Bioinspir. Biomim. 2010, 5, 045002. [CrossRef]

243. Yanoviak, S.P.; Munk, Y.; Kaspari, M.; Dudley, R. Aerial manoeuvrability in wingless gliding ants (Cephalotes atratus). Philos. Trans. R. Soc. Lond. B Biol. Sci. 2010, 277, 2199-2204. [CrossRef]

244. Munk, Y.; Yanoviak, S.P.; Koehl, M.A.R.; Dudley, R. The descent of ant: Field-measured performance of gliding ants. J. Exp. Biol. 2015, 218, 1393-1401. [CrossRef]

245. Zeng, Y.; Lam, K.; Chen, Y.; Gong, M.; Xu, Z.; Dudley, R. Biomechanics of aerial righting in wingless nymphal stick insects. Interface Focus 2017, 7, 20160075. [CrossRef]

246. Sechzer, J.A.; Folstein, S.E.; Geiger, E.H.; Mervis, R.F.; Meehan, S.M. Development and maturation of postural reflexes in normal kittens. Exp. Neurol. 1984, 86, 493-505. [CrossRef]

247. Diamond, J.M. Why cats have nine lives. Nature 1988, 332, 586-587. [CrossRef]

248. Kane, T.R.; Scher, M.P. A dynamical explanation of the falling cat phenomenon. Int. J. Solids Struct. 1969, 5, 663-670. [CrossRef]

249. Arabyan, A.; Tsai, D. A distributed control model for the air-righting reflex of a cat. Biol. Cybern. 1998, 79, 393-401. [CrossRef]

250. Galli, J.R. Angular momentum conservation and the cat twist. Phys. Teach. 1995, 33, 404-407. [CrossRef]

251. Kawano, F.; Yoneshima, H.; Ishihara, A.; Igarashi, M.; Ohira, Y. Hindlimb suspension inhibits air-righting due to altered recruitment of neck and back muscles in rats. Jpn. J. Physiol. 2004, 54, 229-242. [CrossRef]

252. Masuda, K.; Yamaguchi, T. Abnormal air-righting reflex in striatal rats. Jpn. J. Physiol. 2000, 50, $163-166$. [CrossRef]

253. Schönfelder, J. The development of air-righting reflex in postantal growing rabbits. Behav. Brain Res. 1984, 11, 213-221. [CrossRef]

254. Burrows, M.; Cullen, D.A.; Dorosenko, M.; Sutton, G.P. Mantises exchange angular momentum between three rotating body parts to jump precisely to targets. Curr. Biol. 2015, 25, 786-789. [CrossRef]

255. Jusufi, A.; Goldman, D.I.; Revzen, S.; Full, R.J. Active tails enhance arboreal acrobatics in geckos. Proc. Natl. Acad. Sci. USA 2008, 105, 4215-4219. [CrossRef]

256. Chang-Siu, E.; Libby, T.; Tomizuka, M.; Full, R.J. A lizard-inspired active tail enables rapid maneuvers and dynamic stabilization in a terrestrial robot. In Proceedings of the 2011 IEEE/RSJ International Conference on Intelligent Robots and Systems, San Francisco, CA, USA, 25-30 September 2011; pp. 1887-1894. [CrossRef] 
257. Libby, T.; Moore, T.Y.; Changsiu, E.; Li, D.; Cohen, D.; Jusufi, A.; Full, R.J. Tail-assisted pitch control in lizards, robots and dinosaurs. Nature 2012, 481, 181-184. [CrossRef]

258. Gillis, G.B.; Bonvini, L.A.; Irschick, D.J. Losing stability: Tail loss and jumping in the arboreal lizard Anolis carolinensis. J. Exp. Biol. 2009, 212, 604-609. [CrossRef]

259. Higham, T.E.; Davenport, M.S.; Jayne, B.C. Maneuvering in an arboreal habitat: The effects of turning angle on the locomotion of three sympatric ecomorphs of Anolis lizards. J. Exp. Biol. 2001, 204, 4141-4155. [CrossRef]

260. Hickman, G.C. The mammalian tail: A review of functions. Mammal Rev. 1979, 9, 143-157. [CrossRef]

261. O'Connor, S.M.; Dawson, T.J.; Kram, R.; Donelan, J.M. The kangaroo's tail propels and powers pentapedal locomotion. Biol. Lett. 2014, 10, 559-578. [CrossRef]

262. Kawata, K. A note on the function of the tail in the Macropodinae. Int. Zoo Yearb. 1971, 11, 23. [CrossRef]

263. Moore, J.; Gutmann, A.; Craig, M.; McKinley, P. Exploring the role of the tail in bipedal hopping through computational evolution. In Artificial Life Conference Proceedings, 13 September 2013; MIT Press: Cambridge, MA, USA; pp. 11-18. [CrossRef]

264. Patel, A.; Boje, E. On the conical motion of a two-degree-of-freedom tail inspired by the cheetah. IEEE Trans. Robot. 2015, 31, 1555-1560. [CrossRef]

265. Patel, A.; Boje, E.; Fisher, C.; Louis, L.; Lane, E. Quasi-steady state aerodynamics of the cheetah tail. Biol. Open 2016, 5, 1072-1076. [CrossRef]

266. Patel, A.; Braae, M. Rapid acceleration and braking: Inspirations from the cheetah's tail. In Proceedings of the 2014 IEEE International Conference on Robotics and Automation, Hong Kong, China, 31 May-7 June 2014; pp. 793-799. [CrossRef]

267. Patel, A.; Braae, M. Rapid turning at high-speed: Inspirations from the cheetah's tail. In Proceedings of the 2013 IEEE/RSJ International Conference on Intelligent Robots and Systems, Hong Kong, China, 31 May-7 June 2014; pp. 5506-5511. [CrossRef]

268. Briggs, R.; Lee, J.; Haberland, M.; Kim, S. Tails in biomimetic design: Analysis, simulation, and experiment. In Proceedings of the 2012 IEEE/RSJ International Conference on Intelligent Robots and Systems, Vilamoura, Portugal, 7-12 October 2012; pp. 1473-1480. [CrossRef]

269. Jusufi, A.; Kawano, D.T.; Libby, T.; Full, R.J. Righting and turning in mid-air using appendage inertia: Reptile tails, analytical models and bio-inspired robots. Bioinspir. Biomim. 2010, 5, 045001. [CrossRef]

270. Walker, C.; Vierck, C.J., Jr.; Ritz, L.A. Balance in the cat: Role of the tail and effects of sacrocaudal transection. Behav. Brain Res. 1998, 91, 41-47. [CrossRef]

271. Dyhr, J.P.; Morgansen, K.A.; Daniel, T.L.; Cowan, N.J. Flexible strategies for flight control: An active role for the abdomen. J. Exp. Biol. 2013, 216, 1523-1536. [CrossRef]

272. Jusufi, A.; Zeng, Y.; Full, R.J.; Dudley, R. Aerial Righting Reflexes in Flightless Animals. Integr. Comp. Biol. 2011, 51, 937-943. [CrossRef]

273. Zeglin, G.J. Uniroo-A One Legged Dynamic Hopping Robot. Bachelor's Thesis, Massachusetts Institute of Technology, Cambridge, MA, USA, 1991.

274. Chang-Siu, E.; Libby, T.; Brown, M.; Full, R.J.; Tomizuka, M. A nonlinear feedback controller for aerial self-righting by a tailed robot. In Proceedings of the 2013 IEEE International Conference on Robotics and Automation, Karlsruhe, Germany, 6-10 May 2013; pp. 32-39. [CrossRef]

275. De, A.; Koditschek, D.E. The Penn Jerboa: A platform for exploring parallel composition of templates. arXiv 2015, arXiv:1502.05347.

276. Saab, W.; Rone, W.S.; Ben-Tzvi, P. Robotic tails: A state-of-the-art review. Robotica 2018, 36, $1263-1277$. [CrossRef]

277. Truong, T.N.; Phan, H.V.; Park, H.C. Design and demonstration of a bio-inspired flapping-wing-assisted jumping robot. Bioinspir. Biomim. 2019, 14, 036010. [CrossRef]

278. Slow Motion Video of Vertical Jump with Synchronized Vertical Force Data. Available online: https: //www.youtube.com/watch?v=qN3apht8zRs (accessed on 20 August 2020).

279. Nauwelaerts, S.; Aerts, P. Take-off and landing forces in jumping frogs. J. Exp. Biol. 2006, 209, 66-77. [CrossRef]

280. Alexander, R.M. Elastic Mechanisms in Animal Movement; Cambridge University Press: Cambridge, UK, 1988.

281. Domokos, G.; Várkonyi, P.L. Geometry and self-righting of turtles. Philos. Trans. R. Soc. Lond. B Biol. Sci. 2007, 275, 11-17. [CrossRef] 
282. Chen, D.; Zheng, W.; Huang, Y.; Shen, Q. The design and optimization of a hopping robot's tipping mechanism. Chin. J. Mech. Eng. 2011, 47, 17-23. [CrossRef]

283. Zhao, J.; Yang, R.; Xi, N.; Gao, B.; Fan, X.; Mutka, M.W.; Xiao, L. Development of a miniature self-stabilization jumping robot. In Proceedings of the 2009 IEEE/RSJ International Conference on Intelligent Robots and Systems, St. Louis, MO, USA, 10-15 October 2009; pp. 2217-2222. [CrossRef]

284. Ho, T.; Lee, S. A novel design of a robot that can jump and roll with a single actuator. In Proceedings of the 2012 IEEE/RSJ International Conference on Intelligent Robots and Systems, Vilamoura, Portugal, 7-12 October 2012; pp. 908-913. [CrossRef]

285. Armour, R.H. A Biologically Inspired Jumping and Rolling Robot. Ph.D. Thesis, University of Bath, Bath, UK, 2010.

286. Kovac, M.; Savioz, G.; Zufferey, J.C.; Floreano, D.; Srinivasan, M.; Ellington, C. Towards the Self Deploying Microglider, Gliding Flight and Bioinspired Wing Folding Mechanism. In Proceedings of the International Symposium on Flying Insects and Robots, Ascona, Switzerland, 12-17 August 2007; pp. 61-62.

287. Kovac, M.; Guignard, A.; Nicoud, J.D.; Zufferey, J.C.; Floreano, D. A 1.5 g SMA-actuated microglider looking for the light. In Proceedings of the 2007 IEEE International Conference on Robotics and Automation, Roma, Italy, 10-14 April 2007; pp. 367-372. [CrossRef]

288. Kovač, M.; Zufferey, J.C.; Floreano, D. Towards a self-deploying and gliding robot. In Flying Insects and Robots; Springer: Berlin/Heidelberg, Germany, 2009; pp. 271-284. [CrossRef]

289. Desbiens, A.L.; Pope, M.; Berg, F.; Teoh, Z.E.; Lee, J.; Cutkosky, M. Efficient jumpgliding: Theory and design considerations. In Proceedings of the 2013 IEEE International Conference on Robotics and Automation, Karlsruhe, Germany, 6-10 May 2013; pp. 4451-4458. [CrossRef]

290. Zhang, Z.; Chen, D.; Chen, K. Analysis and comparison of three leg models for bionic locust robot based on landing buffering performance. Sci. China Technol. Sci. 2016, 59, 1413-1427. [CrossRef]

291. Dupeyroux, J.; Serres, J.R.; Viollet, S. AntBot: A six-legged walking robot able to home like desert ants in outdoor environments. Sci. Robot. 2019, 4, eaau0307. [CrossRef]

292. Chen, X.; Ghadirzadeh, A.; Folkesson, J.; Björkman, M.; Jensfelt, P. Deep reinforcement learning to acquire navigation skills for wheel-legged robots in complex environments. In Proceedings of the 2018 IEEE/RSJ International Conference on Intelligent Robots and Systems, Madrid, Spain, 1-5 October 2018; pp. 3110-3116. [CrossRef]

293. Pfeiffer, M.; Shukla, S.; Turchetta, M.; Cadena, C.; Krause, A.; Siegwart, R.; Nieto, J. Reinforced imitation: Sample efficient deep reinforcement learning for mapless navigation by leveraging prior demonstrations. IEEE Robot. Autom. Mag. 2018, 3, 4423-4430. [CrossRef]

294. Hwu, T.; Wang, A.Y.; Oros, N.; Krichmar, J.L. Adaptive robot path planning using a spiking neuron algorithm with axonal delays. IEEE Trans. Cogn. Dev. Syst. 2017, 10, 126-137. [CrossRef]

295. Antonelo, E.A.; Schrauwen, B. On learning navigation behaviors for small mobile robots with reservoir computing architectures. IEEE Trans. Neur. Netw. Learn. Syst. 2014, 26, 763-780. [CrossRef]

296. Wu, Q.; Lin, C.M.; Fang, W.; Chao, F.; Yang, L.; Shang, C.; Zhou, C. Self-organizing brain emotional learning controller network for intelligent control system of mobile robots. IEEE Access 2018, 6, 59096-59108. [CrossRef]

297. Nichols, E.; McDaid, L.J.; Siddique, N. Biologically inspired SNN for robot control. IEEE Trans. Cybern. 2013, 43, 115-128. [CrossRef]

Publisher's Note: MDPI stays neutral with regard to jurisdictional claims in published maps and institutional affiliations.

(C) 2020 by the authors. Licensee MDPI, Basel, Switzerland. This article is an open access article distributed under the terms and conditions of the Creative Commons Attribution (CC BY) license (http://creativecommons.org/licenses/by/4.0/). 